\title{
卟啉类光敏剂在光动力治疗中的应用研究
}

\author{
汪凌云* 曹德榕 \\ (华南理工大学化学与化工学院 广州 510640)
}

\begin{abstract}
摘要 作为光动力疗法中至关重要的决定性因素, 光敏剂的研究受到越来越多的重视. 重点综述了多种新型卟啉类化 合物、酞菁类化合物和二氢卟吩类化合物的合成及其在光动力治疗中的应用研究.
\end{abstract}

关键词 光敏剂; 卟啉; 光动力治疗

\section{Research Advances of Porphyrin Photosensitizers in Photodynamic Therapy}

\author{
Wang, Lingyun* Cao, Derong \\ (School of Chemistry and Chemical Engineering, South China University of Technology, Guangzhou 510640)
}

\begin{abstract}
Photosensitizers have attracted increasing attention as a critical role in photodynamic therapy (PDT). In this paper, some important results in recent years for novel porphyrin, phthalocyanine and chlorin derivatives as photosensitizer are reviewed.

Keywords photosensitizer; porphyrin; photodynamic therapy (PDT)
\end{abstract}

卟啉是一类由 4 个吡咯环通过次甲基相连形成的共 轭骨架大环化合物, 分子结构中 4 个吡咯环的 8 个 $\beta$ 位 和 4 个中位(meso)的氢原子均可被其它基团所取代, 生 成各种卟啉衍生物. 它不仅具有独特的生理活性, 而且 与癌细胞有独特的亲和力, 在医学上作为光动力治疗法 (photodynamic therapy, PDT) 的抗癌光敏剂 ${ }^{[1,2]}$.

卟啉最基本的共同结构是卟吩核, 即 4 个吡咯单元 的氮原子朝向中心并通过 4 个叔碳原子桥连在一起的封 闭而连续的芳香性共轭体系, 卟啉是卟吩的衍生物. 把 卟吩环的 4 个中位叔碳原子用氮原子代替产生的化合物 叫做四氮杂卟琳, 再在 4 个吡咯环的外围并上 4 个苯环 之后产生的化合物叫作酞菁, 也被称作四氮杂四苯并卟 啉.

第一代光敏剂有: 血卟啉衍生物、二血卟啉醚和 Photofrin，已获多国政府的药监部门批准应用于临床， 多为混合制剂, 在体内的滞留时间长, 避光时间需 4 周 以上. 此外, 由于体内红血球和光散射的原因, 第一代 光敏剂的光穿透组织的深度有限 $(0.5 \mathrm{~cm}$ 以下 $)$, 限制了 PDT 在较大肿瘤上的治疗应用. 第二代光敏剂有: 间-
四羟基苯基二氢卟酚、初卟啉锡、亚甲基蓝和亚甲苯蓝、 苯卟啉衍生物、唒菁类、得克萨卟啉、 $n$-天门冬酰基二 氢卟酚、金丝桃素、血啉甲醚、苯并卟啉衍生物单酸以 及生物体内生物合成卟啉的原初化合物 $\delta$-氨基乙酰丙 酸等. 它们已进入临床研究阶段, 尚未批准正式临床应 用，部分地克服了第一代光敏剂的缺点，更加符合理想 光敏剂的特点, 表现为光敏期短, 作用的光波波长较大, 因而增加了作用的深度, 产生的单态氧也较多, 对肿瘤 更有选择性. 第三代光敏剂多为第二代光敏剂的衍生 物，如氨基酸偶联光敏剂、聚合物偶联光敏剂、蛋白质 或糖偶联光敏剂等，它们是在第二代光敏剂上粘附或引 入一些具有生物特性或分子识别功能的化学物质, 进一 步提高对肿瘤组织的选择性, 目前尚处在动物研究阶 段. 好的 PDT 光敏剂应具有以下特点: (1)在可见光的红 区 $(>650 \mathrm{~nm})$ 有强吸收; (2)单重态氧和三重态量子产 率高; (3)低暗毒性; (4)在癌组织上可被选择性吸收, 对 健康组织, 特别是皮肤应不吸收或少吸收; (5)容易大量 合成，容易保存; (6)根据药物动力学的要求，多余的药 物应能很快从体内排泄. 卟啉类光敏剂的设计与合成及

* E-mail: lingyun@scut.edu.cn

Received May 31, 2012; revised June 27, 2012; published online July 4, 2012

Project supported by the National Natural Science Foundation of China (No. 20904010) and the Special Funded Projects of Pearl River in Guangzhou City of Nova of Science and Technology (No. 2012J2200009).

国家自然科学基金(No. 20904010)和广州市珠江科技新星专项(No. 2012J2200009)资助项目. 
其在肿瘤光动力疗法中的应用是新的研究热点, 本文综 述了近几年来关于卟啉类光敏剂的最新研究成果, 希望 能为研究者设计合成更优秀的卟啉类光敏剂提供一定 的参考.

\section{1 卟啉类光敏剂}

\section{1 合成方法}

最近, Senge $\mathrm{e}^{[3]}$ 对不对称 meso-位取代的卟啉和功能 化卟啉的合成方法进行了综述. 卟琳的合成方法主要有 Adler 合成法 ${ }^{[4]}$ 和 Lindsey 合成法 ${ }^{[5]}$ 两种经典方法, 现在 的合成方法大多数是在这两种方法的基础上改进和发 展起来的. 对于分子结构完全对称的卟啉化合物, 采用 相应 2,5 位上不含取代基的吡咯与甲醛(或苯甲醛)经缩 合、氧化生成(Eq. 1); 或者采用 2 位上含甲基(或亚甲基) 的吡咯经自身缩合、氧化而得到(2 位上的甲基用来产生 次甲基桥 ${ }^{[6]}$. 而分子结构不对称的卟啉化合物, 先分别 合成各个取代吡咯, 然后将各吡咯单体逐步连接成环 ${ }^{[7,8]}$. 根据连环的顺序以及合成过程中所采用中间体的 不同, 这类方法可分为 “ $2+2$ ” 合成法和 “ $3+1$ ” 合成 法(Eq. 2).

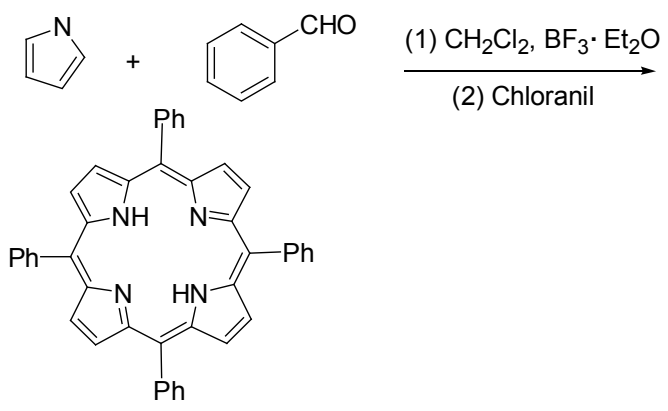

4<smiles>CCC(=O)OCc1cc(C=O)cc(OC)c1</smiles>

\section{2 硝基卟啉和羧基卟啉}

高浓度的 NO 是有毒的, 可诱导肿瘤细胞调亡、阻 止肿瘤转移、帮助巨噬细胞杀死肿瘤细胞. Liu 等 ${ }^{[9]}$ 合成 了一类可在肿瘤细胞中释放 NO 的硝基卟啉化合物 1a 1d, 研究发现, 与正常的 L-02 肝细胞相比, 它们在 BEL-7402 肝癌细胞中的聚集浓度更高, 且具有更高的 细胞杀伤力. 在光照条件下, 它们对乳腺癌 MCF-7 细胞 的抗癌效果与 5 -氟尿嘧啶抗癌药物相当.

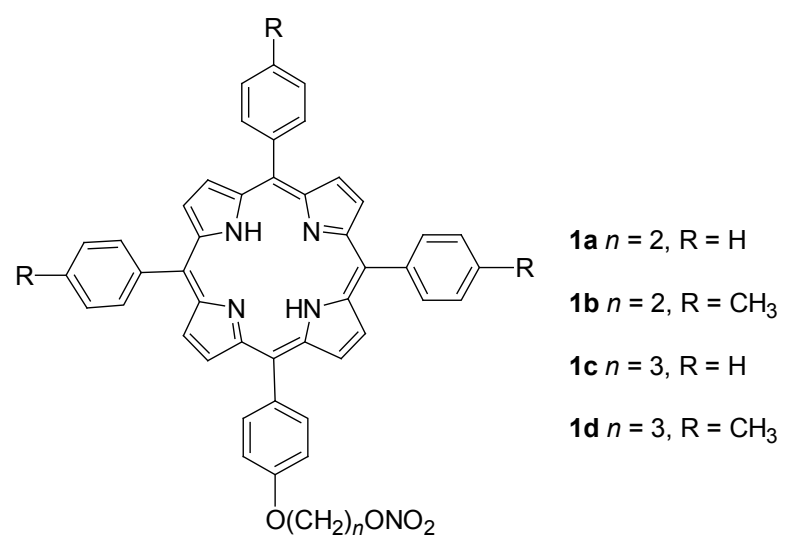

一系列含单烷基羧酸侧链的卟啉衍生物 2 被合 成 ${ }^{[10]}$, 它们具有良好的光稳定性, 其荧光量子产率与四 苯基卟啉相当, 由于存在着亲/疏水平衡, 它们可被放置 于与天然生物膜相类似的胶束、脂质体等体系, 是一种 潜在的光敏剂.

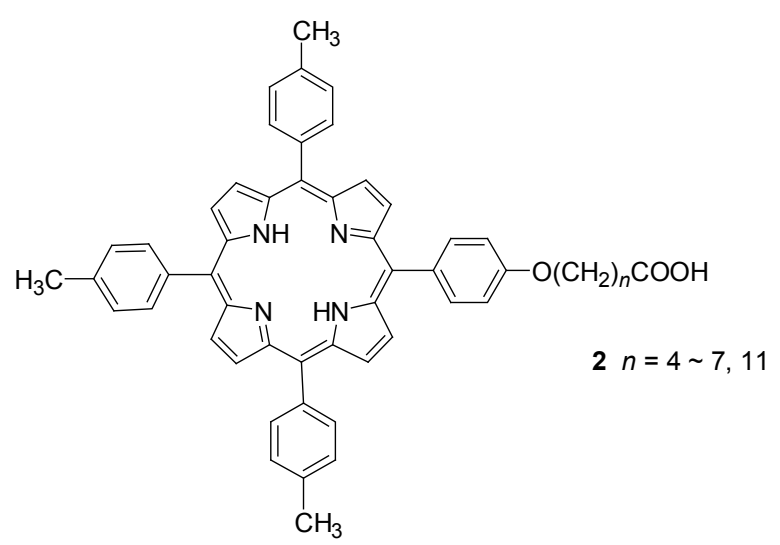

\section{3 糖苷化卟啉}

以改善溶解性及靶向性为目的在光敏剂母体上引 入糖基的研究正成为近年来的研究热点. 2010 年, 张沛 等 ${ }^{[11]}$ 从糖基光敏剂的母体结构、糖基光敏剂分子的构效 关系、糖基的作用机理以及糖基光敏剂的药物动力学和 代谢产物这四个方面对近年来糖基光敏剂的研究现状 进行了综述. 2011 年, Maillard 课题组 ${ }^{[12]}$ 合成了两类糖基 树枝状 meso-四芳基吓啉化合物 $\mathbf{3 a}$ 和 $\mathbf{3 b}, \mathbf{3} \mathbf{a}$ 的糖苷间具 有较大的空间位阻，使得糖基的自由度降低，而 $3 \mathbf{b}$ 在氨 基酸和糖苷间以柔性连接基 $\left(\mathrm{CH}_{2} \mathrm{CH}_{2} \mathrm{CONH}\left(\mathrm{CH}_{2} \mathrm{CH}_{2} \mathrm{O}\right)_{n}\right.$, 
$n=1,2,3)$ 相连，以减少糖苷间空间位阻和增加糖基的 自由度, 氨基酸的引入(甘氨酸或 $L$-苯丙氨酸)改变了光 敏剂的疏水性质, 有利于改善光敏剂的细胞渗透能力和 在癌细胞脂质膜的靶向针定能力, $\mathbf{3 a}$ 和 $\mathbf{3 b}$ 的暗毒性都 很低, 体外 HT29 细胞和 Y79 细胞的存活率达到 100\%。

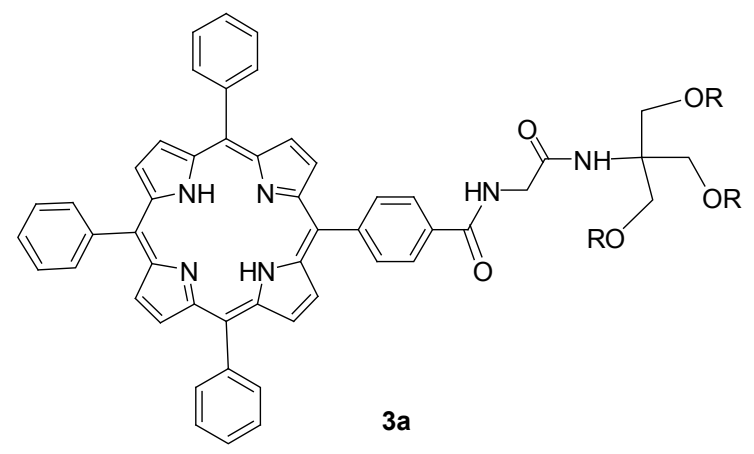<smiles>OC1C(O)C(O)C(O)C(O)C1O</smiles>

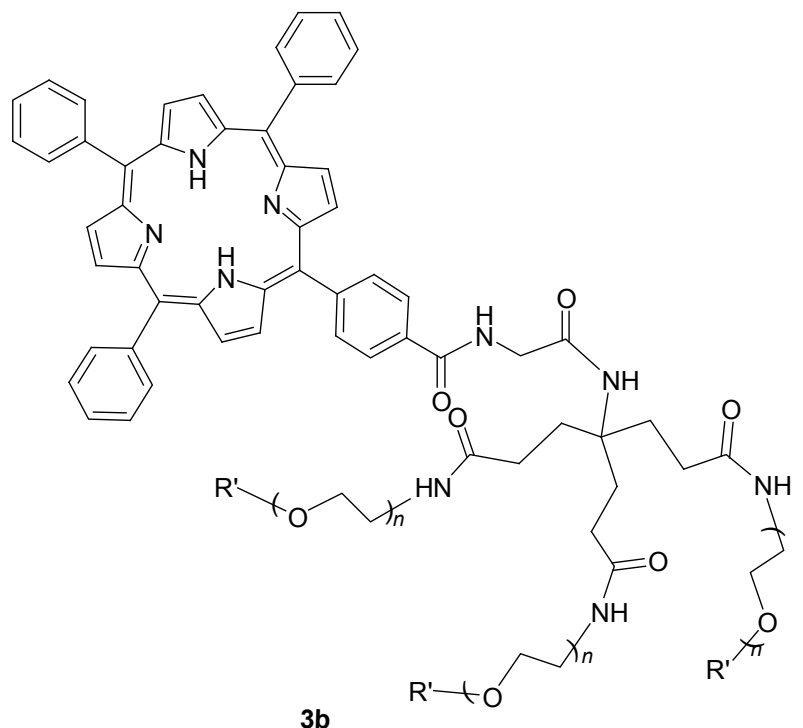

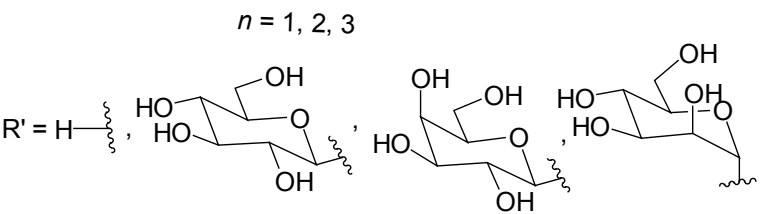

Vedachalam 等 ${ }^{[13]}$ 合成了一类在卟啉的 2 个 meso-位 连接异亚丙基保护的半乳糖的卟啉衍生物 $\mathbf{4 a} \sim \mathbf{4 j}$, 以体 外 HeLa 细胞和 HCT1161 细胞为研究对象, 研究了卟啉 环的另 2 个 meso-位苯基上取代基的位置和电子特性对 其光毒性有影响, 发现在苯基的对位引入供电子基(甲 氧基、甲硫基、3-噻吩基)有利于提高光毒性, 而在苯基 的对位引入吸电子基(氯、硝基)或在苯基的邻位引入供 电子基则使卟啉没有光毒性, 如在卟啉的 4 个 meso 位直
接连接半乳糖, 则使该卟啉衍生物的光毒性最好. 体外 HeLa 细胞对光敏剂的摄取量数据表明: 与 $\mathbf{4 i}$ 和 $\mathbf{4 j}$ 相比, 4e 和 $4 \mathbf{f}$ 几乎没被 HeLa 细胞摄取, 其中卟啉的 4 个 meso 位均被糖基取代的 $4 \mathbf{j}$ 被 HeLa 细胞摄取量比 $\mathbf{4 i ,}, \mathbf{4 e}$ 和 $\mathbf{4 f}$ 高 3 8 倍. 进一步研究表明, 光敏剂定位于 HeLa 细胞 的溶酶体中，而非文献报道的线粒体或内质的网状组织 中，多腺苷二磷酸多聚酶抗原[poly(ADP-ribose) polymerase, PARP]断裂实验表明 $\mathbf{4 j}$ 引起细胞调亡是通过 caspase 依赖性的调亡机理进行的.

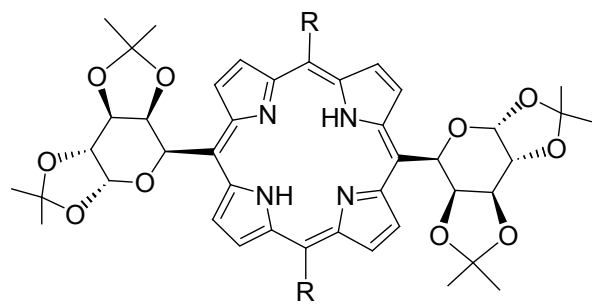

4a $\mathrm{R}=\mathrm{Ph}, \mathbf{4 b} \mathrm{R}=2,6-\mathrm{Me}_{2} \mathrm{C}_{6} \mathrm{H}_{3} \mathrm{O}, \mathbf{4} \mathbf{c} \mathrm{R}=4-\mathrm{MeC}_{6} \mathrm{H}_{4} \mathrm{O}$ 4d $\mathrm{R}=4-\mathrm{MeC}_{6} \mathrm{H}_{4} \mathrm{~S}, 3 \mathbf{e} \mathrm{R}=4-\mathrm{CF}_{3} \mathrm{C}_{6} \mathrm{H}_{4} \mathrm{O}, \mathbf{4 f} \mathrm{R}=\mathrm{C}_{6} \mathrm{~F}_{5}$,

4g R $=4-\mathrm{ClC}_{6} \mathrm{H}_{4}$, 4h R = 4- $\mathrm{NO}_{2} \mathrm{C}_{6} \mathrm{H}_{4}$

4i $\mathrm{R}=3$-thienyl, $4 \mathbf{j} \mathrm{R}=$ sugar

黄齐茂等 ${ }^{[14]}$ 将天然产物姜黄素与特定卟啉桥连, 合成一种对肿瘤兼具光动力治疗和药化治疗作用的新 型姜黄素桥连卟啉光敏剂 $5 \mathbf{a} \sim \mathbf{5 d}$ ，同时中药活性分子 可通过卟啉在肿瘤部位的富集达到一定靶向效果，两者 还可相互协同进一步增强光敏剂的抗癌活性. 初步光敏 活性研究表明: 该光敏剂与 DNA 结合能力较强, 在光 照条件下对 pBR322 质粒 DNA 有良好的切割效果.

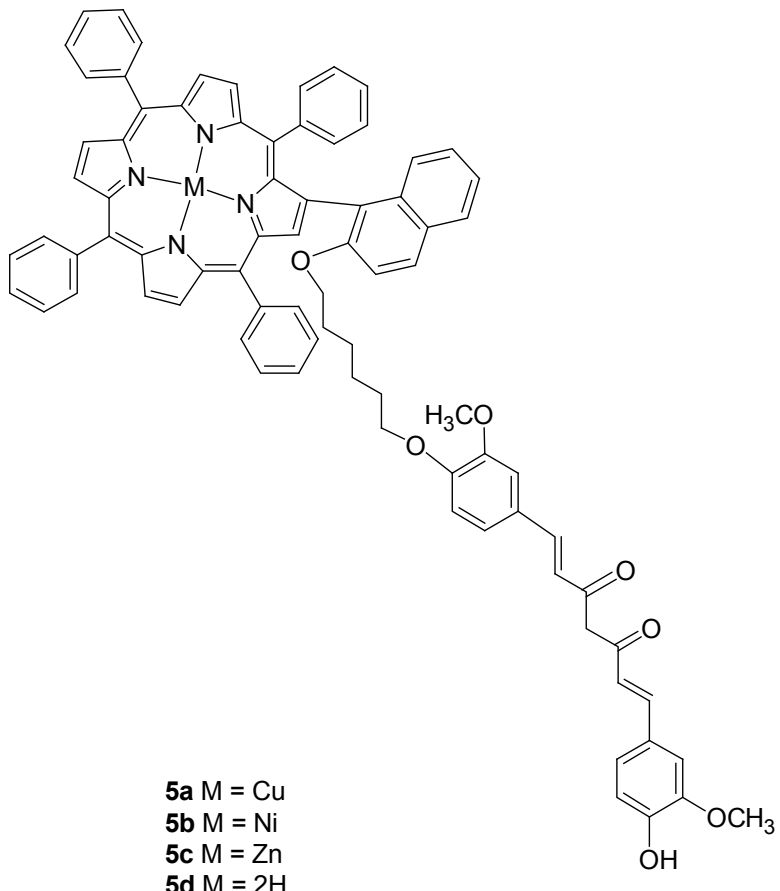




\section{4 蛋白质或肽偶联卟啉}

为了克服卟啉类光敏剂水溶性差、在水溶液中易聚 集和对肿瘤组织亲和性差的不足, 合成蛋白质、氨基酸 或肽偶联卟啉的光敏剂备受关注. Giuntini 等 ${ }^{[15]}$ 最近对 蛋白质或肽与卟㕲偶联的合成方法进行了综述，总结了 偶联反应的各种反应类型，如表 1 所示.

一些卟啉-氨基酸偶联物显示了有趣的 PDT 特性, 如可高特异性地嵌入 DNA 序列、增加光敏剂被肿瘤细 胞的摄取量、增加在水溶液中的水溶性、与细胞膜存在 特殊的相互作用等. Serra 等 ${ }^{[16]}$ 合成了一系列卟啉-氨基 酸偶联物 $6 \mathbf{a} \sim \mathbf{6 d}$, 这些化合物在脂质体中很稳定, 并能 有效地渗入到肿瘤 $\mathrm{HeLa}$ 细胞和正常 $\mathrm{HaCaT}$ 细胞的细胞 质中, 即使在 $24 \mathrm{~h}$ 的细胞培养过程中也未显现暗毒性, 与正常 $\mathrm{HaCaT}$ 细胞相比, $\mathbf{6 a} \sim \mathbf{6 d}$ 对肿瘤 $\mathrm{HeLa}$ 细胞表现 出更强的光毒性, 其中 $6 \mathbf{a}$ 表现出最高的光毒性.

在人类的许多恶性肿瘤(如淋巴癌、乳腺癌、脑癌、 卵巢癌、结肠癌和睪丸癌) 表面有鞘糖脂 Gb3 受体, Amessou 等 ${ }^{[17]}$ 将可选择性识别 Gb3 受体的志贺毒素 B 亚单位 $(\mathrm{STxB})$ 与卟啉糖化合物 7a 偶联, 得到 7a-STxB 光敏剂. 与未偶联 STxB 的 $7 \mathbf{b}$ 相比, 7a-STxB 的单线态

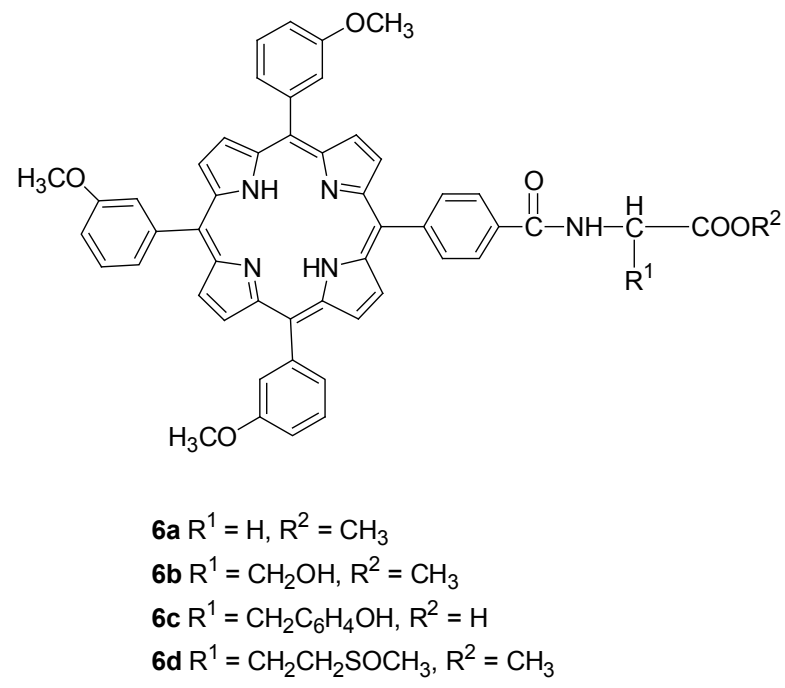

氧量子产率降低, 只有 0.13 , 是 $7 \mathbf{b}$ 的 $1 / 3$, 但 $\mathbf{6 a - S T x B}$ 的光敏活性是 7b 的 5 倍. 其原因是, STxB 是一个非常 稳定的分子, 可越过细胞障碍进入细胞内部, STxB 介导 地逆行运输光敏剂到癌细胞使 7a-STxB 光敏剂获得最 优的细胞毒性.

表 1 卟啉与蛋白质或肽的偶联方法

Table 1 Ligation strategies for the conjugation of porphyrin to peptides and proteins

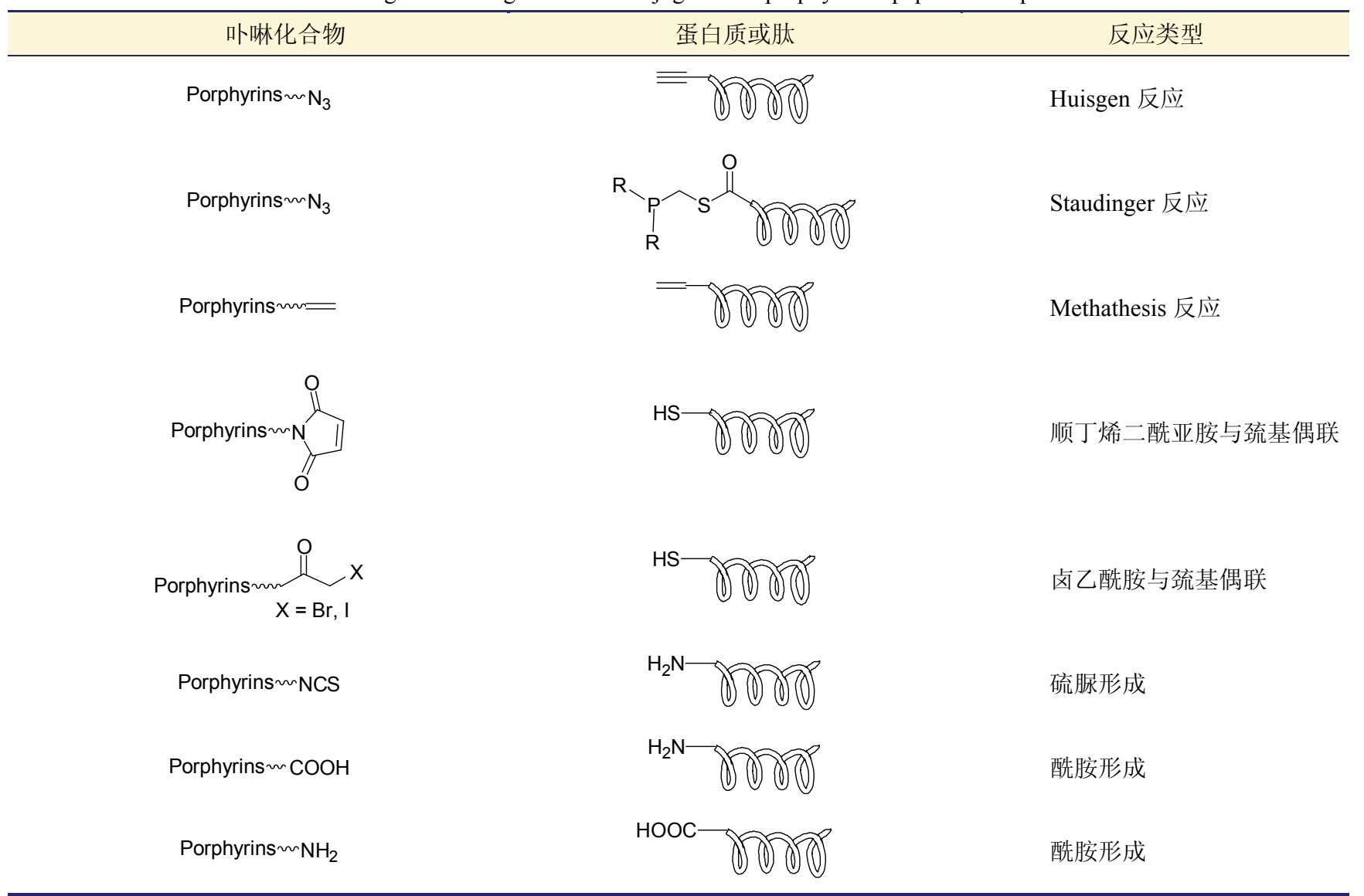



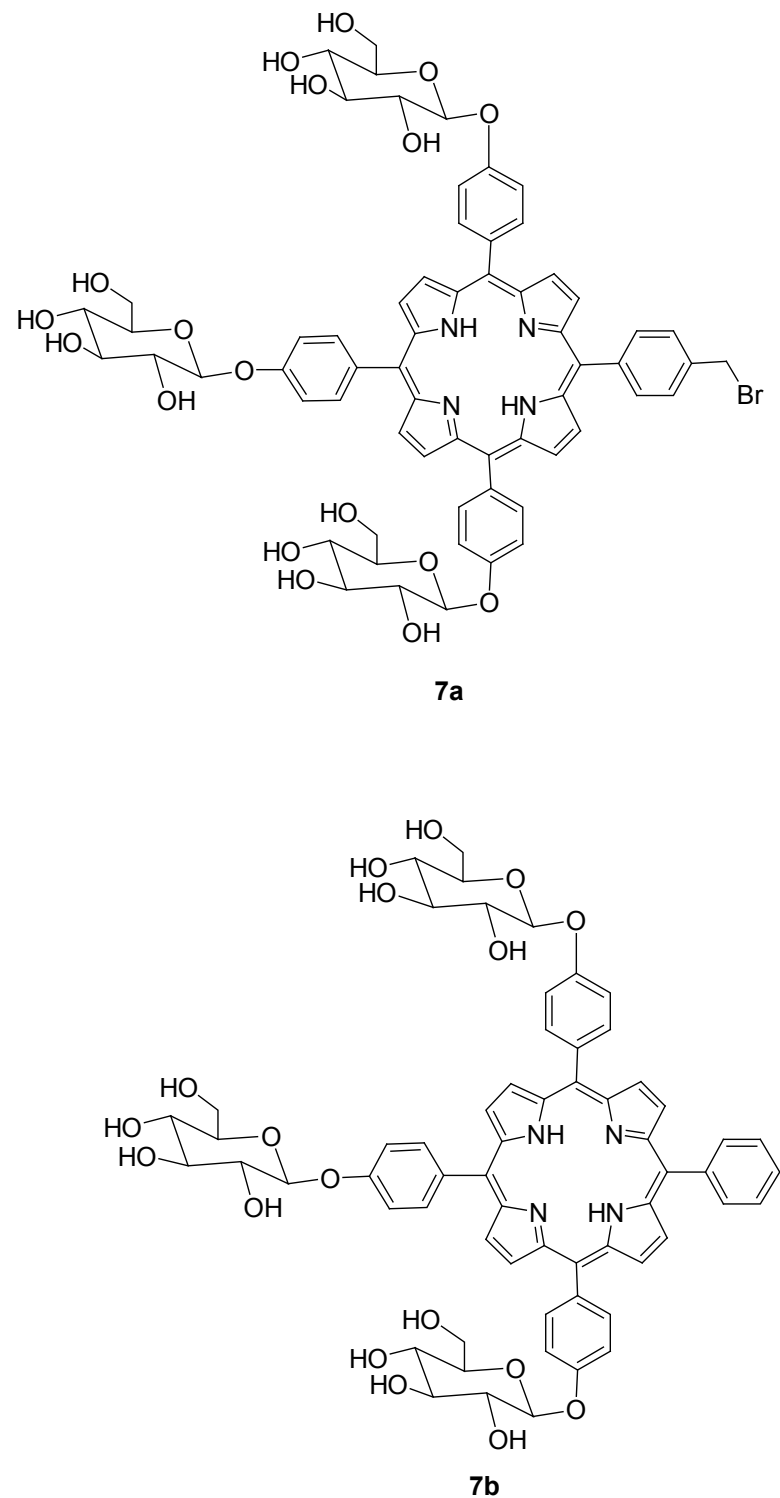

与卟啉单体相比, 吓啉二聚体具有更强的光捕获能 力, 由于 RGD 序列肽可识别肿瘤细胞外基质中过度表 达的 $\alpha_{v} \beta_{3}$ 整合素, Sol 等 ${ }^{[18]}$ 采用 Grubbs 催化剂通过烯烃
交叉易位反应合成了含有 RGD 序列肽间隔基的卟啉二 聚体，产率为 $57 \% \sim 60 \%$ ，以体外 K562 细胞为研究对 象, 考察了该卟啉二聚体的光动力效率, 结果表明其比 目前临床使用的 Photofrin 具有更好的光毒性.

Makky 等 ${ }^{[19]}$ 采用表面压力测试、苂光光谱、动态光 散射和 QCM-D 手段研究了甘露糖基树枝状卟啉化合物 与伴刀豆球蛋白(Con A) 的特异性相互作用. 虽然卟啉 是强荧光物质，由于在水溶液中易发生聚集使得卟啉的 苂光很弱，如在水溶液中加入非极性分子(如脂质体和 蛋白)可使聚集体解聚而导致荧光增强. 苂光光谱数据 表明: 在 7a 9 的水溶液中加入 Con A, 苂光谱图的形 状未发生改变, 但其发射峰的强度大大增加, 解聚过程 与卟啉结构中是否含有糖单元无关，只与卟啉大环与 Con A 疏水区域的相互作用有关. 8a $\sim 8 \mathrm{c}$ 与 Con A 的结 合常数 $\left(K_{\mathrm{b}}\right)$ 的数值分别为 $0.18 \times 10^{5}, 1.74 \times 10^{5}$ 和 $1.67 \times$ $10^{5} \mathrm{~mol}^{-1}, 8 \mathrm{a}$ 没有亲水甘露糖单元是导致其 $K_{\mathrm{b}}$ 数值大大 降低的原因, $8 \mathrm{a}$ 与 Con $\mathrm{A}$ 主要是通过疏水作用结合的, 而 8b $\sim 8 \mathrm{c}$ 与 Con $\mathrm{A}$ 是通过特异性识别和疏水作用的协 同作用结合.

\section{5 氟卟啉}

氟及全氟烷基的引入使卟啉的光学性质有较大变 化，利用这些性质可以制备多种多样的光电材料; 此外, 由于含氟化合物具有强的生理活性, 因此含氟卟啉有可 能和生物组织相互作用而显示抗肿瘤作用. 曾卓课题组 ${ }^{[20]}$ 和 Leroy 课题组 ${ }^{[21]}$ 分别对含氟卟啉的研究进展进行了 综述, 2011 年, Costa 等 ${ }^{[22]}$ 专门综述了 5,10,15,20-四(五氟 苯基)卟啉与各种亲核试剂(胺、醇、硫醇、含 $\mathrm{N}$ 原子的 杂环化合物)的亲核反应.

Hirohara 等 ${ }^{[23]}$ 对 5,10,15,20-四(五氟苯基)卟啉进行 功能化, 合成了一系列 $S$-糖苷化卟啉 $(\mathbf{9 a} \sim 9 \mathbf{d})$ 和金属卟 啉化合物 $9 \mathrm{e} \sim 9 \mathrm{~h}$, 由于 $\mathrm{S}$ 原子重原子效应的影响, 产生 单线态氧量子产率的顺序是: $9 \mathrm{a}, 9 \mathrm{e}<9 \mathrm{~b}, 9 \mathrm{f}<9 \mathrm{c}, 9 \mathrm{~g}$, 但

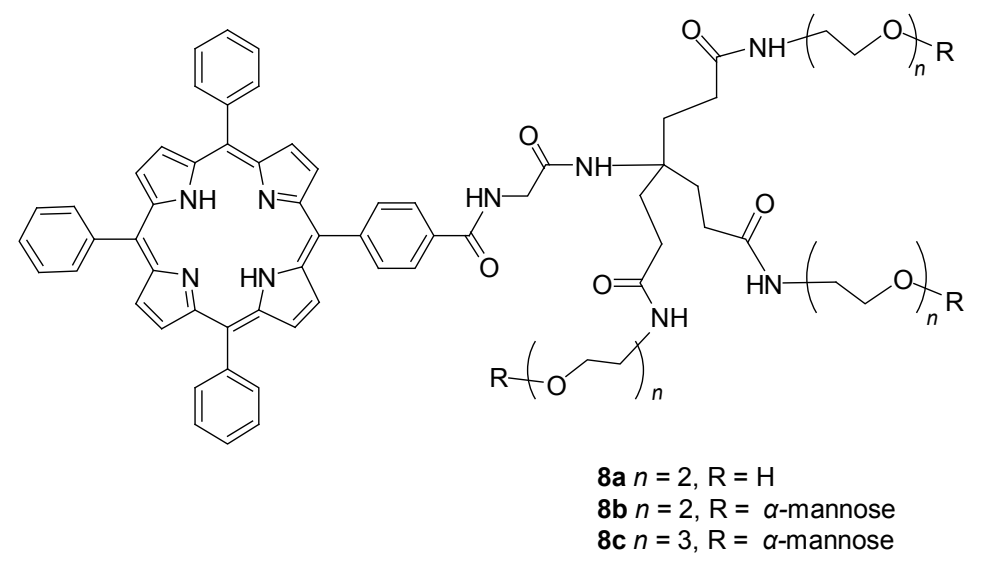


$\operatorname{Pt}(\mathrm{II})$ 卟啉化合物 9d, 9h 的单线态氧量子产率非常低, 其 机理尚不清楚. 以体外 HeLa 细胞为研究对象, 体外光 毒性数据表明: 有糖苷保护基的卟啉和金属卟啉化合物 9a 9d 均没有光细胞毒性, 但糖苷化卟啉和金属卟啉 化合物 9e $\sim 9 \mathrm{~h}$ 表现出良好的光细胞毒性, 由于糖组分 有利于光敏剂被癌细胞摄取和 $\mathrm{S}$ 原子的重原子效应有利 于产生单线态氧, 9f 和 $9 \mathrm{~g}$ 是潜在的光敏剂.

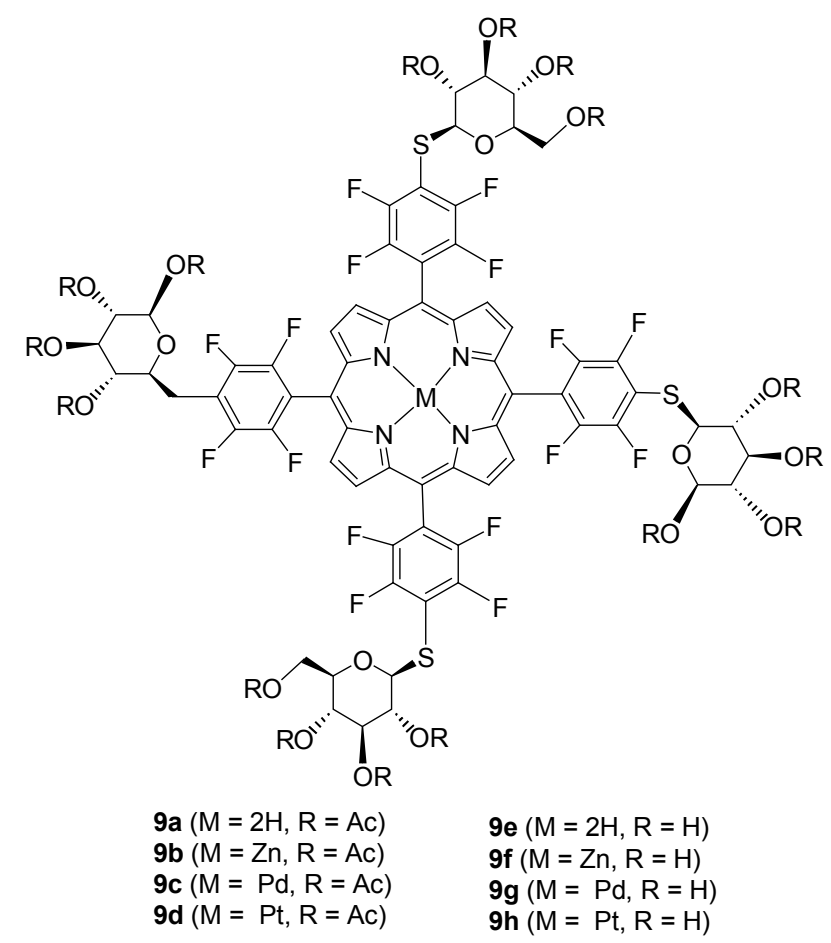

\section{6 近红外吸收的卟啉}

临床上使用的 Photofrin 的最长吸收在 $630 \mathrm{~nm}$, 光 穿透组织的深度小于 $0.5 \mathrm{~cm}$, 如果光敏剂的最大吸收在 $700 \mathrm{~nm}$, 光穿透组织的深度就接近 $0.8 \mathrm{~cm}$, 而 $800 \mathrm{~nm}$ 光 的穿透组织深度就可达到 $1 \mathrm{~cm}$, 因此研制吸收波长在 红外区、近红外区的的新型光敏剂备受关注. 如酞菁配 合物、萘酞菁、紫红素、叶绿素、脱镁叶酸铁、细菌叶 绿素等，它们不仅在更长的可见光区 $(640 \sim 850 \mathrm{~nm})$ 有 更强的吸收, 更重要的是这些以 $\mathrm{Al}$ 或 $\mathrm{Zn}$ 为中心离子的 大环的金属配合物的三线态产率与三线态寿命比第一 代光敏剂大的多.

为了增加卟啉的水溶性, McCarthy 等 ${ }^{[24]}$ 以 meso-四 (对一氨基苯基)卟啉为原料, 高产率地合成了中性的、具 有共轭结构的亲水叶绿素类光敏剂 $10 \mathrm{a}$ 和 $10 \mathrm{~b}$, 葡萄糖 组分的引入增加了疏水卟啉的极性, 该类化合物在红外 和近红外区具有非常好的吸收性能, 最大吸收峰位于 $716 \mathrm{~nm}$, 有利于增加光穿透组织的深度, 提高 PDT 效 果. 将这些光敏剂偶联到葡聚糖涂层的纳米粒子上发 现, 亲水葡萄糖组分的引入有利于光敏剂与纳米粒子偶
联，与商品化的 chlorin e6 相比, 10a 所形成的纳米组分 很稳定，未发生絮凝现象。

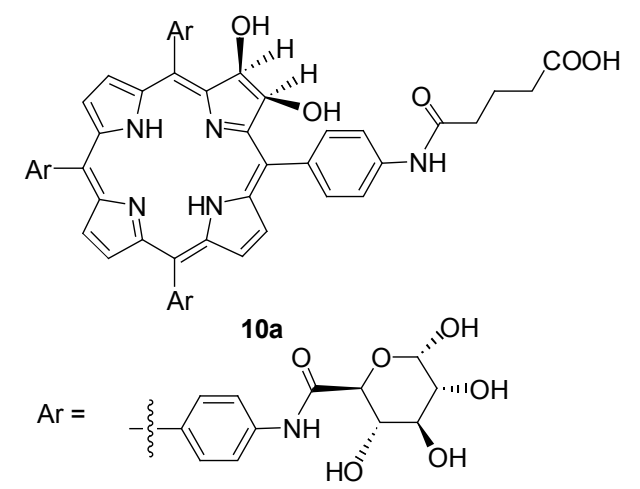

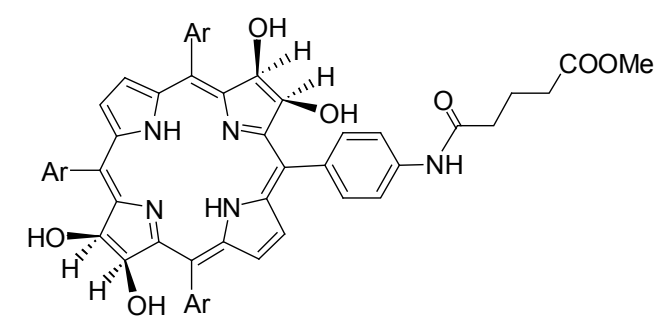

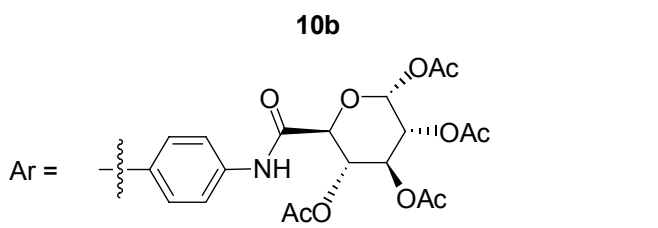

$\mathrm{Li}$ 等 ${ }^{[25]}$ 采用类似羟醛缩合的合成方法, 立体选择 性地合成了 $\beta$ 位含吡啶盐或喹啉盐阳离子基团的长波长 卟啉衍生物 11a 和 11b, 由于吡啶阳离子或喹啉阳离子 基团的吸电子效应，使得 $11 \mathrm{a}$ 和 $11 \mathrm{~b}$ 的 $\mathrm{Q}$ 带吸收波长延 长到 712 763 nm, 光动力研究初步结果表明, 11a 和 11b 显示了对 HeLa 细胞更高的光毒性, 有可能用作光 敏剂.

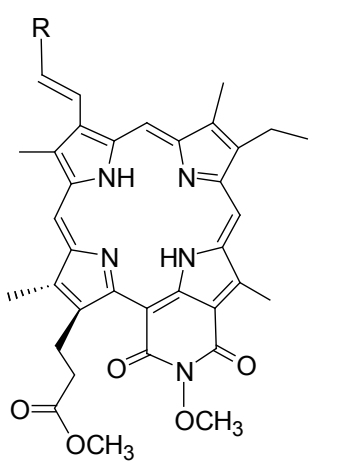

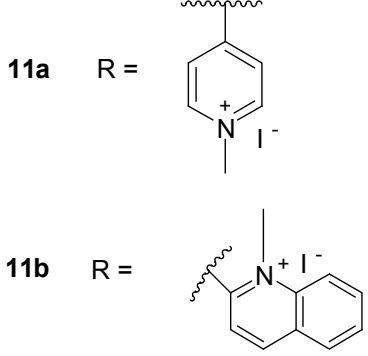

Maillard 课题组 ${ }^{[26]}$ 合成了一系列具有双光子吸收截 面大、线性吸收光谱红移、单线态氧量子产率高的糖基 锌卟啉衍生物 $12 \mathrm{a} \sim 2 \mathrm{~d}$, 可用于单光子和双光子的光动 力治疗. 糖基锌卟啉二聚体和三聚体的荧光量子产率比 糖基锌卟啉单体低 1.5 倍到 2 倍, 但糖基锌卟啉二聚体 

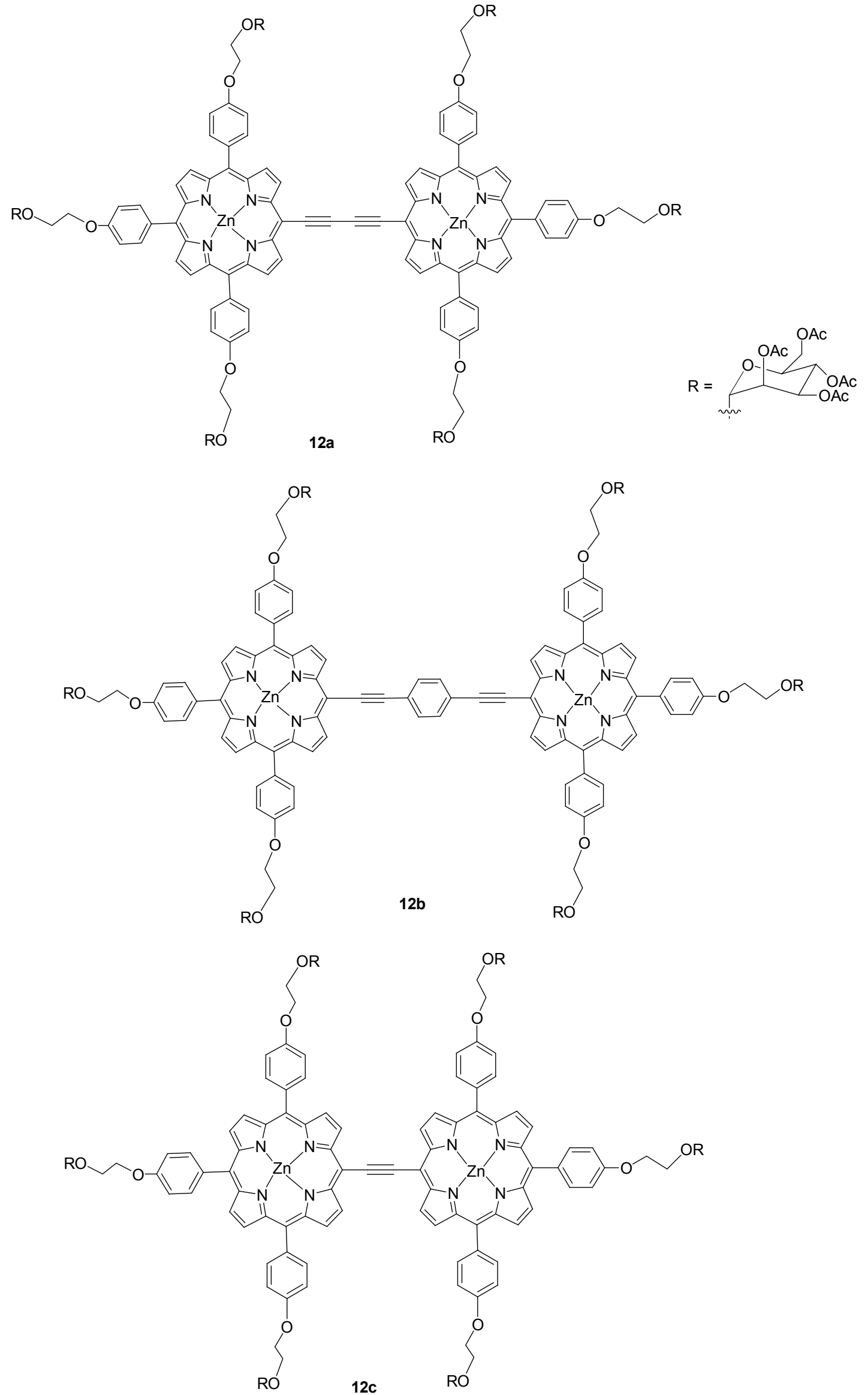


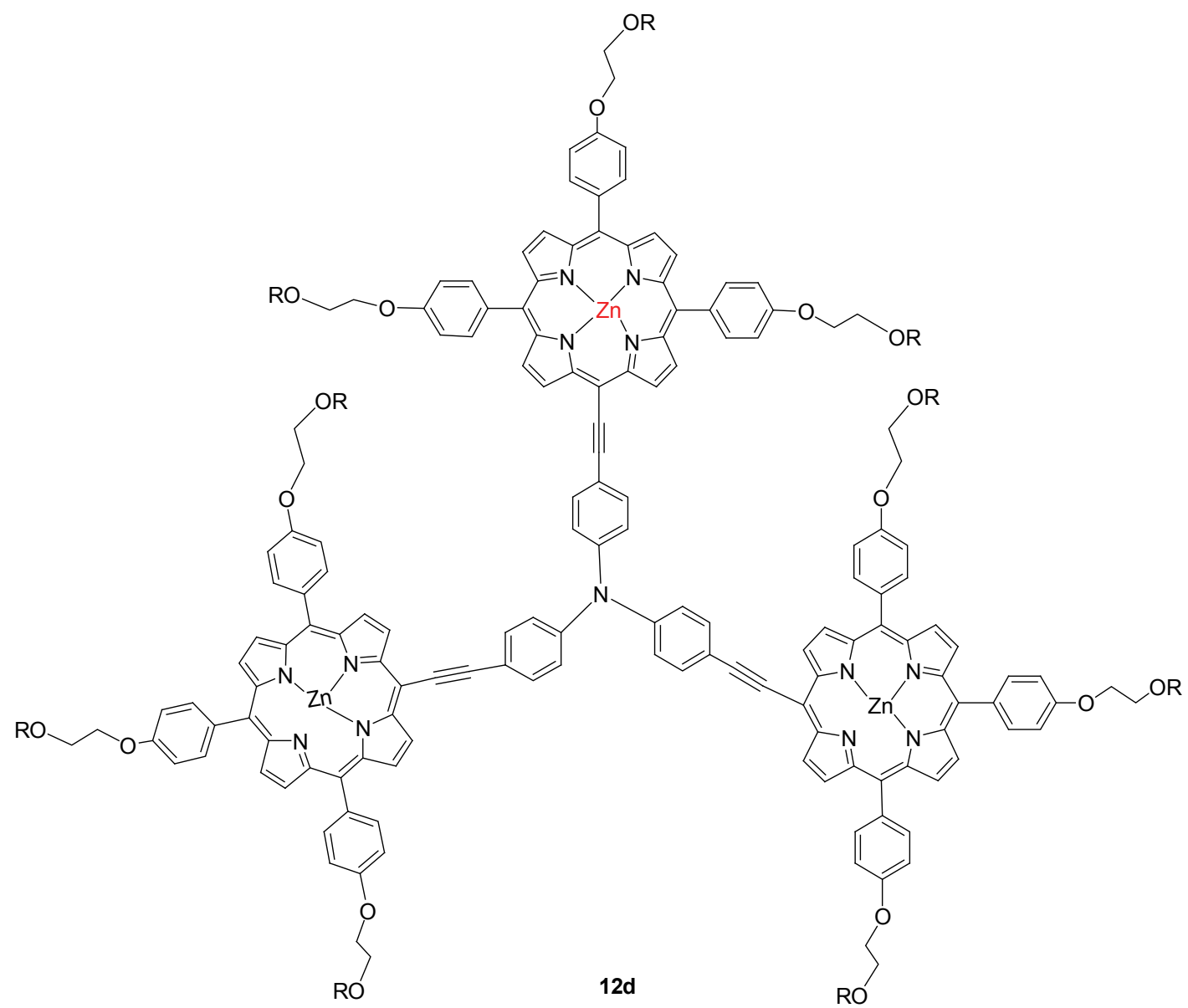

和三聚体的单线态氧量子产率可达 $0.43 \sim 0.75,12 \mathrm{a}$ 的荧 光发射峰在 619 和 $712 \mathrm{~nm}$. 由于这些化合物中含有 $\alpha$ 甘露糖单元, 预计它们可在凝集素过分表达的肿瘤细胞 中靶向聚集, 实现对肿瘤细胞的杀伤作用.

\section{7 特殊结构的卟啉}

近年来, 一些特殊结构的卟啉类化合物一一如缩环 卟啉、异构卟啉和扩展卟啉等, 逐渐引起了化学家们的 关注, 成为卟啉化学中新的研究热点. 王进军课题 组 ${ }^{[27]}$ 和蒋华卫等 ${ }^{[28]}$ 分别综述了环稠卟啉和亚卟啉的研 究进展. 沈珍等近年来报道了一些非经典的卟啉类化合 物, 如通过 “一锅煮” 的方法可方便地合成了一系列三 元卟啉衍生物 ${ }^{[29]}$; 他们 ${ }^{\left[{ }^{[0]}\right.}$ 对 Lindsey 卟啉合成法加以改 进, 用三氟化嗍-乙醚作催化剂, 合成了一系列 $\beta$ 位分别 为二乙基、二环 [2.2.2]辛二烯和二氢萗的三元卟啉衍生 物, 通过逆 Diels-Alder 反应, 还分别得到可苯环和萗环 稠合的三元卟啉分子. 2011 年, 他们 ${ }^{[31]}$ 报道合成了 $m e s o$-位芳基取代的菲并卟啉化合物, 通过在 meso-位苯 环对位引入吸电子 $\left(\mathrm{CN}\right.$ 和 $\left.\mathrm{NO}_{2}\right)$ 和供电子基 $\left(\mathrm{CH}_{3}\right.$ 和 $\left.\mathrm{N}\left(\mathrm{CH}_{3}\right)_{2}\right)$, 考察取代基电子效应对其光谱性能的影响, 研究结果表明 meso-位苯环对位含 $\mathrm{N}\left(\mathrm{CH}_{3}\right)_{2}$ 的卟啉化合
物在 $1200 \mathrm{~nm}$ 处出现了 $\mathrm{Q}_{00}$ 带.

\section{2 酞菁类光敏剂}

酞菁又称四苯并四氮杂卟啉，具有以下特点：(1)理 化性质稳定，最大吸收波长位于易透过人体组织的红光 区域, 在红外区的吸收系数较血卟啉衍生物高 $10 \sim 50$ 倍, 因此进行 PDT 治疗时, 只需要 $0.2 \sim 0.5 \mathrm{mg} / \mathrm{kg}$ 的剂 量; (2)酞菁在体内的动力学作用比血卟啉衍生物快得 多, 经注射后 1 $3 \mathrm{~h}$ 内在肿瘤组织中达到最大值, 并在 $24 \mathrm{~h}$ 内从体内清除干净，皮肤光敏反应时间短暂; (3)具 有较高的荧光效率, 荧光量子产率比血卟啉衍生物高 21 倍.

\section{1 合成方法}

自由酞菁由于相互间存在着较强的缔合行为(由大 $\pi$ 键导致的分子间相互作用)使溶解度变得非常小，限制 了其应用，而非对称的酞菁化合物由于其结构上的特殊 性，具有更优异的性能. 相对于对称酞菁多种多样的合 成方法, 不对称唒菁化合物的合成方法较少. 最常见的 一种方法是统计法 ${ }^{[32]}$ ，即将两种分别含 $\mathrm{A}$ 或 $\mathrm{B}$ 取代基的 酞菁前体以 $3: 1$ 的比例概率性随机缩合反应，以期望 
获得 $\mathrm{AAAB}$ 型不对称酞菁. 前体通常有邻苯二氧、1,3二亚胺基异吲哚等. 这种合成方法存在的主要问题是合 成产物的分离和纯化困难. 袁吉志等 ${ }^{[33}$ 曾设计合成了 一个大位阻基团 $\left(\mathrm{CPh}_{3}\right)$ 取代的不对称酞菁化合物(Eq. 3), 并利用其较大的位阻来减少产物间的缔合行为和提高 产物的溶解性能, 从而使其分离变得简便. 反应产物可 以通过相对较简单的色谱法即可分离, 且产率可达 $37.1 \%$.

第二种方法为 Leznoff 等 ${ }^{[34]}$ 发展的使产物分离相对 较简便有效的方法一高分子化法, 将取代的二亚氨基异 吲哚或邻苯二氯预先连接到不溶的高分子侧链上形成 一种固相的聚合物前体，然后与过量的另一种二亚胺基 异吲哚或邻苯二氧反应, 得到的混合产物中的对称酞菁 成分可以用不溶解高分子链的溶剂洗去, 余下的产物再 经过反应把不对称酞菁从高分子链上脱下来, 最终产率 为 $20 \% \sim 25 \%$ (Scheme 1). 此方法关键点在于要事先合 成一种与高分子相连的邻苯二㲵功能单元, 难度较大, 限制了该方法的进一步广泛应用.

第三种方法为 Kobayashi 等 ${ }^{[35]}$ 描述的亚酞菁法. 先 用含 $\mathrm{A}$ 取代基的邻苯二氰单体合成三个 $\mathrm{A}$ 基取代的亚
酞菁，然后此亚酞菁与 $\mathrm{B}$ 取代的琥珀酰亚胺或二亚胺 基异吲哚开环扩展为 $\mathrm{AAAB}$ 型不对称酞菁(Eq. 4). 该 方法具有高效性、选择性和产物容易分离等优点, 但其 缺点就是亚酞菁的扩环反应仍然存在着不确定性，随机 反应能产生六种酞菁化合物，使得总的产率仍然较低， 低于 $15 \%$.

\section{2 酞菁及金属酞菁衍生物}

酞菁配合物中，可变的结构因素主要有中心离子、 环周边取代基和轴向配体的空间位阻. 中心离子对酞菁 配合物抗癌活性的影响是它们影响酞菁配合物的光敏 化反应能力的结果，已证实中心金属离子具有闭壳层电 子结构(如 $\mathrm{Al}, \mathrm{Zn}$ 和 $\mathrm{Si}$ ) 的唒菁配合物的三线态寿命远大 于中心离子为开壳层电子结构的过渡金属酞菁配合物. Sesalan 等 ${ }^{[36]}$ 合成了阳离子型的水溶性 $\mathrm{Cu}, \mathrm{Co}, \mathrm{Zn}$ 过渡 金属酞菁配合物 13a 13c，13a 和 13b，具有相近的与 DNA 键连能力和单线态氧量子产率, 且 $13 \mathrm{a}$ 和 $13 \mathrm{~b}$ 在水 中的单线态氧量子产率比其在 DMSO 中更高, 在水中, 产生单线态氧量子产率的顺序是: $13 \mathrm{a}>13 \mathrm{c}>13 \mathrm{~b}$. 由于 单线态氧可损伤细胞中的 DNA、蛋白和其他大分子，引 起细胞调亡和死亡，因此，该阳离子过渡金属酞菁配合<smiles>N#CC1=C(OCCOC(c2ccccc2)(c2ccccc2)c2ccccc2)OCCOC(c2ccccc2)(c2ccccc2)c2ccccc2O1</smiles><smiles>COCCOc1c(O)c(OC)cc(OC)c1O</smiles>

(1) $\mathrm{C}_{4} \mathrm{H}_{9} \mathrm{OLi}$ refulx $45 \mathrm{~min}$ (2) $\mathrm{H}_{2} \mathrm{O}$

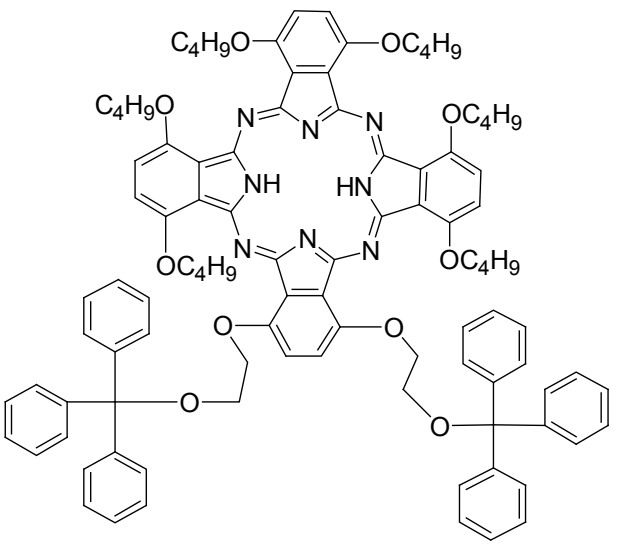

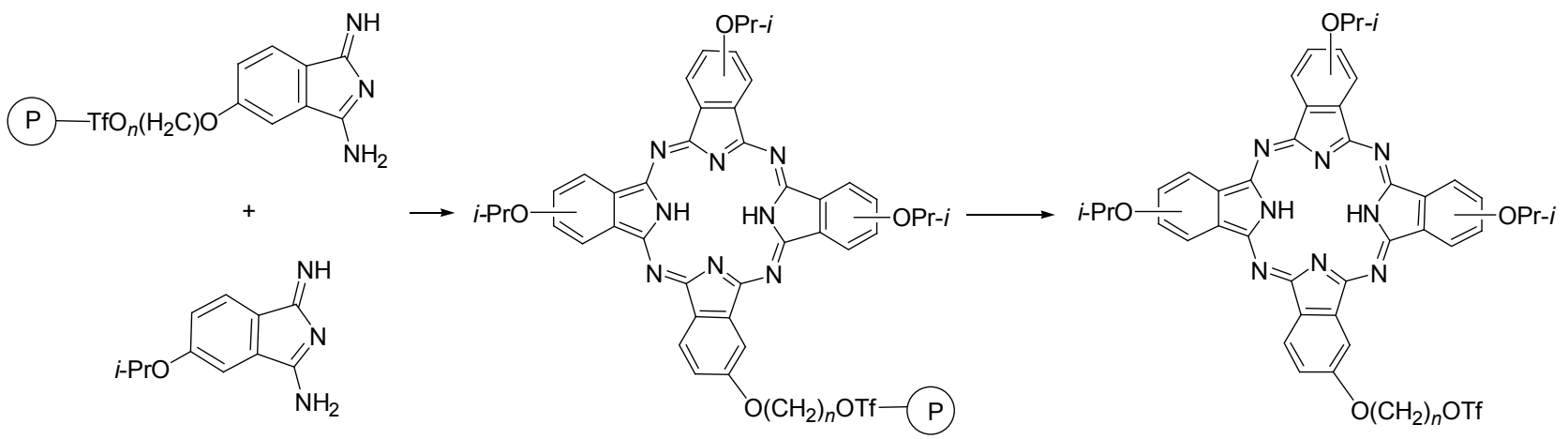

Scheme 1 


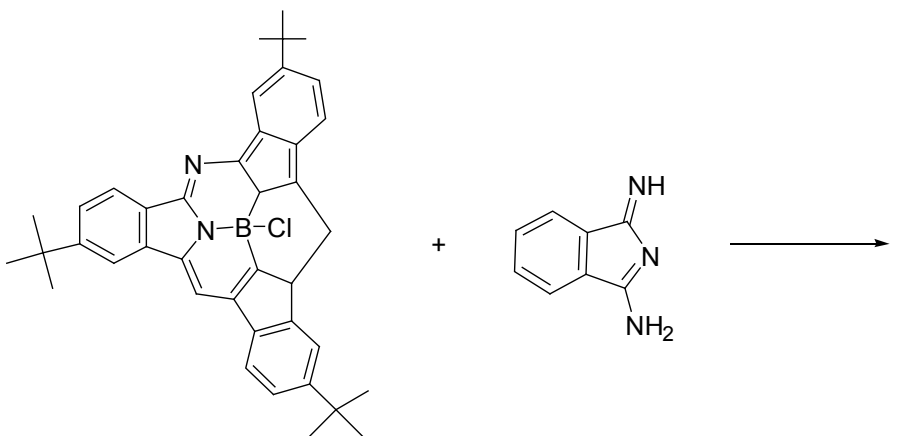

物可通过静电作用与 DNA 发生键连并达到光断裂的目 的，是光断裂 DNA 的活性成分.

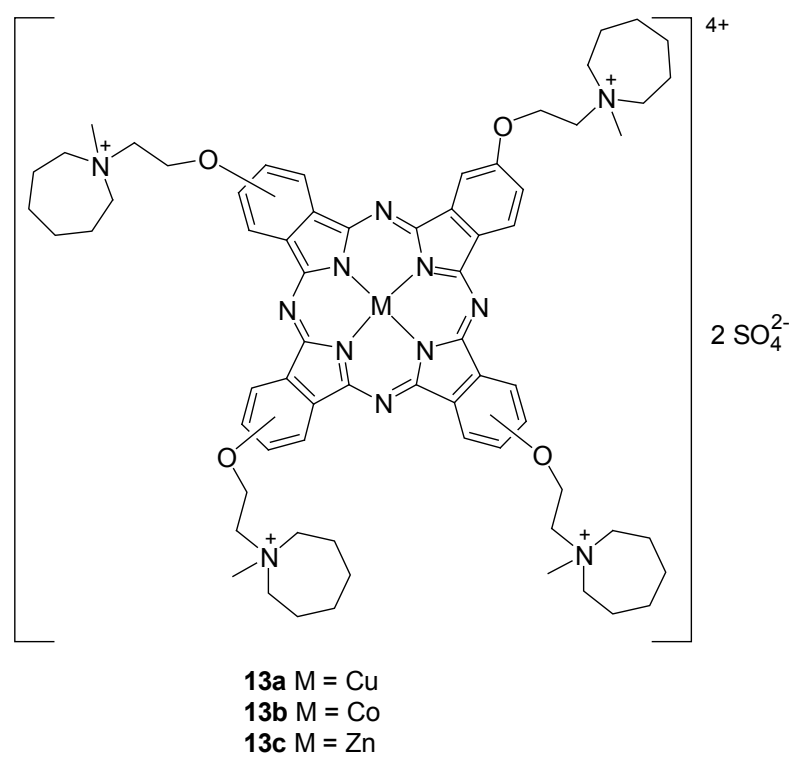

如果光敏剂和单克隆抗体或蛋白连接, 光敏剂就可 以很容易在肿瘤细胞上找到落脚点, 有利于光敏剂在肿 瘤组织中的选择性富集. 但卟㕲或酞菁和抗体蛋白连接 绝非易事, 因为在溶液中进行偶连反应时, 卟啉或酞菁 往往会进入蛋白的疏水链所形成的口袋中, 而不与蛋白 在所希望的位置共价连结. $\mathrm{Ke}$ 等 ${ }^{[37]}$ 成功合成了多肽偶 联酞菁的光敏剂 14, 在酞菁 $\alpha$ 位引入亲水的侧链具有降 低聚集程度、增加酞菁大环双亲性、促进活性氧生成和 增加细胞摄取量的作用. 14 在 DMF 中没有发生聚集, $700 \mathrm{~nm}$ 处显示弱的发射峰, 荧光量子产率为 0.07 , 但其 单线态氧量子产率高达 0.84. 与直肠癌细胞 HT29 作用 的研究结果表明, 14 在细胞培养液中发生较严重的聚集 现象, 没有暗毒性, 但表现出细胞毒性. 此外, 还研究 了 14 在含 HT29 肿瘤裸鼠组织中分布情况, 注入光敏剂 $72 \mathrm{~h}$ 后, 肿瘤细胞中的光敏剂浓度比其他组织中的浓度 更高, 上述结果表明光敏剂中引入多肽有利于提高癌细 胞对光敏剂的摄取、癌细胞穿透能力和细胞内活性氧浓

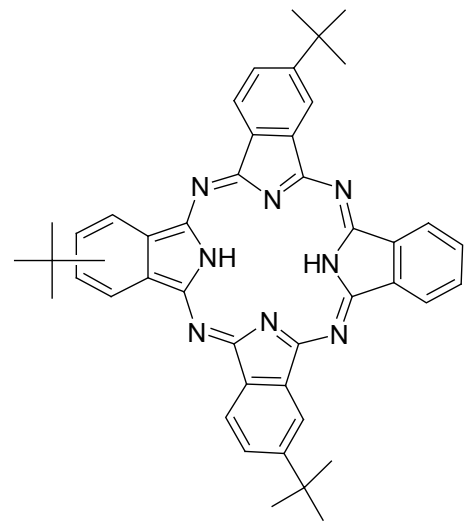

度, 14 是一种潜在的 PDT 光敏剂.

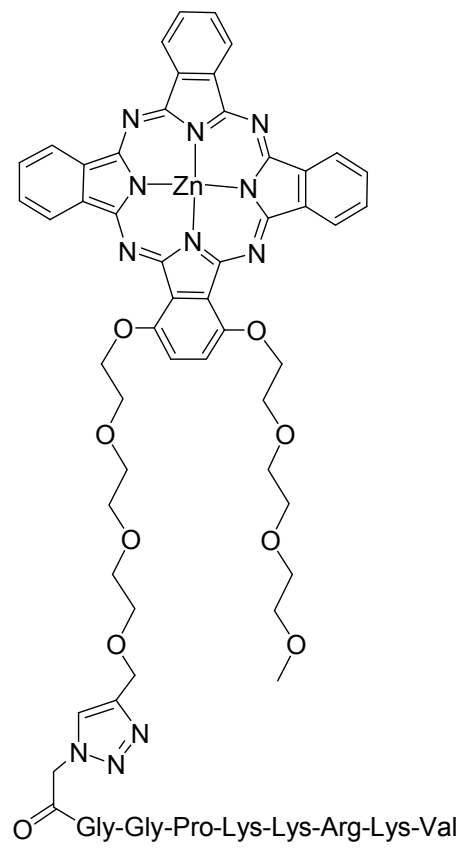

14

酞菁类光敏剂的环取代基由于影响到药物在体内 的转运和肿瘤组织对药物的摄取以及穿透癌细胞的能 力等, 是决定光敏剂药性的重要因素. 由于亲脂性酞菁 不能直接溶于水、难代谢，易造成皮肤光毒性，因此关 于水溶性、两亲性酞菁合成研究较多，如磺基、羧基、 膦基等取代的阴离子型和 $N, N$-二乙胺丙基、吡啶基、二 甲胺基乙氧基等取代的阳离子型; 此外, 研究表明正电 性的光敏剂可直接作用于线粒体, 有利于癌症治疗. 研 究最多且较深入的是磺化酞菁光敏剂, 磺化程度对其体 外的光敏效应有影响, 磺化度影响磺化酞菁在水溶液中 的聚集倾向，磺化度增加，不易聚集，光敏化反应能力 增强, 肿瘤的选择性摄取率增加. 但增大磺化度即增加 亲水性, 其细胞穿透能力减弱, 其中二磺酸铝酞菁被认 为是最有效的, 被看作是 PDT 候选药物 ${ }^{[38]}$. 因此同时含 亲水性和亲脂性取代基即两性取代酞菁配合物成为研 
究热点, 其表现出较高的 PDT 活性, 细胞膜穿透能力 强.

在酞菁结构中引入冠醚和香豆素单元可增加酞菁 在许多有机溶剂中的溶解度, 有利于其在 PDT、生物模 拟、均相催化、碱金属、碱土金属和镧系金属提取方面 的应用, 如 Camur 等 ${ }^{[39]}$ 分别在轴向 $(\beta$ 位) 和非轴向位置 ( $\alpha$ 位)引入香豆素冠醚取代基得到的 $\mathrm{Zn}, \mathrm{Co}, \mathrm{Cu}$ 酞菁类 化合物 15a 15f, 冠醚取代基有利于光敏剂进入细胞, 研究了酞菁类光敏剂的环取代基及其位置对其光物理 (荧光寿命和量子产率)、光化学(单线态氧和光降解量子 产率)和电化学性质有影响, 由于 $\mathrm{Co}(\mathrm{II}), \mathrm{Cu}(\mathrm{II})$ 的顺磁 性, $\mathrm{Co}, \mathrm{Cu}$ 酞菁化合物显示弱的光物理、光化学性质, $\mathrm{Zn}$ 酞菁化合物(15c 和 15f)被用作研究对象, $15 \mathrm{c}$ 和 $15 \mathrm{f}$ 在 DMSO 中的的发射峰分别为 692 和 $708 \mathrm{~nm}$, 但 $\mathbf{1 5 f}$ 的荧 光量子产率比 $15 \mathrm{c}$ 更高, 分别为 0.14 和 0.09 (均在 DMSO 溶剂中), $15 \mathrm{c}$ 和 $15 \mathrm{f}$ 的单线态氧量子产率分别为 0.54 和 0.65 , 表明它们可用作 PDT 的光敏剂, 同时, 香豆素冠 醚取代基的引入也增加了酞菁化合物的光降解稳定性, 由于苯环上引入取代基位置的不同导致酞菁类光敏剂 极性的差异, $\beta$ 位取代的酞菁类光敏剂更容易发生聚集 现象.

由于龀齿洞内细菌表面带负电荷, Longo 等 ${ }^{[40]}$ 首次 将阳离子脂质体作为载体, 将铝酞菁化合物运送到龇齿 洞内, 体外试验和临床研究发现光照后龉齿洞内细菌数 量减少了 $82 \%$, 表明 PDT 方法可用于口腔感染的消毒. Gauna 等 ${ }^{[41]}$ 合成了 2 个新型的阳离子锌酞菁化合物
$16 \mathrm{a}$ 和 $16 \mathrm{~b}, 16 \mathrm{a}$ 和 $16 \mathrm{~b}$ 的最大吸收峰相近, 分别在 686 和 $678 \mathrm{~nm}$, 但 $16 \mathrm{~b}$ 的单线态氧量子产率数值要比 $16 \mathbf{a}$ 高, 分别为 0.67 和 0.42 . 研究了它们对人类鼻咽癌 $\mathrm{KB}$ 细胞 的光动力作用效果, 当 $16 \mathrm{a}$ 的浓度大于 $10 \mu \mathrm{mol} / \mathrm{L}$ 或 $\mathbf{1 6 b}$ 的浓度为 $20 \mu \mathrm{mol} / \mathrm{L}$ 时表现出暗毒性, 光照条件下, 16a 和 $16 \mathbf{b}$ 均显示高的细胞毒性, 其半抑制浓度 $\left(\mathrm{IC}_{50}\right)$ 分别 为 1.45 和 $10.5 \mu \mathrm{mol} / \mathrm{L}$, 表明通过硫原子将烷基链与酞 菁连接的 16a 具有更好的细胞毒性. 共聚焦显微镜显示 由于 16a 具有更好的双亲性, 16a 的肿瘤选择性摄取率 更高, 且定位于 $\mathrm{KB}$ 细胞的溶菌体内.

对酞菁而言, 增加正电荷数目和降低疏水性可增加 其对细菌的 PDT 效率, Tempesti 等 ${ }^{[42]}$ 通过亚酞菁的扩环 反应和甲基化反应合成了一系列不对称的含 $\mathrm{N}$ 一杂环 (吡啶环和吡嗪环)阳离子酞菁化合物, 酞菁组分远离带 正电荷基团构成疏水部分以形成两亲光敏剂. 单线态氧 量子产率的顺序是 $17 \mathrm{~b}>17 \mathrm{c}>17 \mathrm{a}$, 抗真菌活性结果表 明, 17b 和 17c 可更高效率的灭活 C. albicans. 该研究表 明两亲性阳离子酞菁化合物可用于光动力灭活微生物.

Bai 等 ${ }^{[43]}$ 采用 “一锅煮” 的方法经酯交换反应和环 化反应合成了 3 个 $\mathrm{PEG}$ 功能化的酞菁 $18 \mathrm{a} \sim 18 \mathrm{c}$, 产率 为 7\% 23\%, 在 $\mathrm{DMF}$ 中 $18 \mathrm{a} \sim 18 \mathrm{c}$ 米发生聚集，其单线 态氧量子产率为 $0.53 \sim 0.57$. 以体外人腺癌 HT29 细胞 和人肝癌 $\mathrm{HepG} 2$ 细胞为研究对象, $\mathbf{1 8 a} \sim 18 \mathrm{c}$ 均未显示细 胞暗毒性, 在红光 $((\lambda>610 \mathrm{~nm})$ 照射下, 18a 和 18b 的半 抑制浓度 $\left(\mathrm{IC}_{50}\right)$ 要比 $18 \mathrm{c}$ 低得多, 分别为 $0.34,0.25$ 和

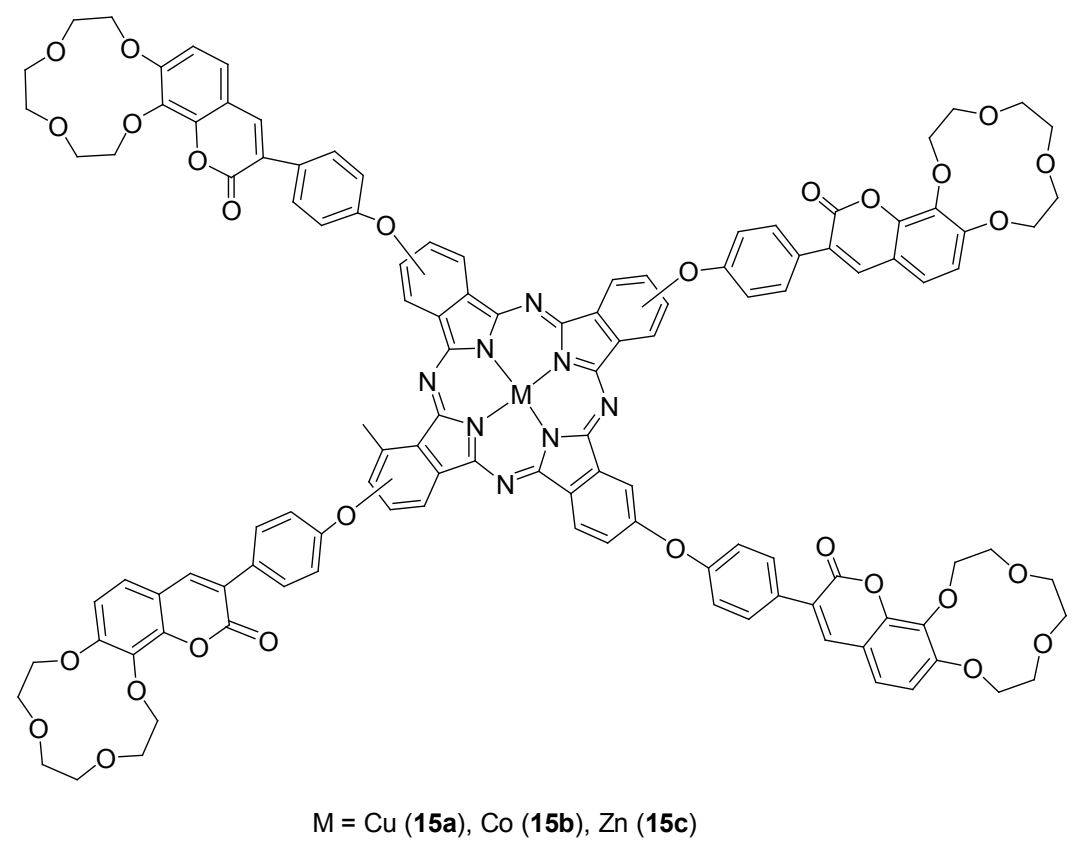




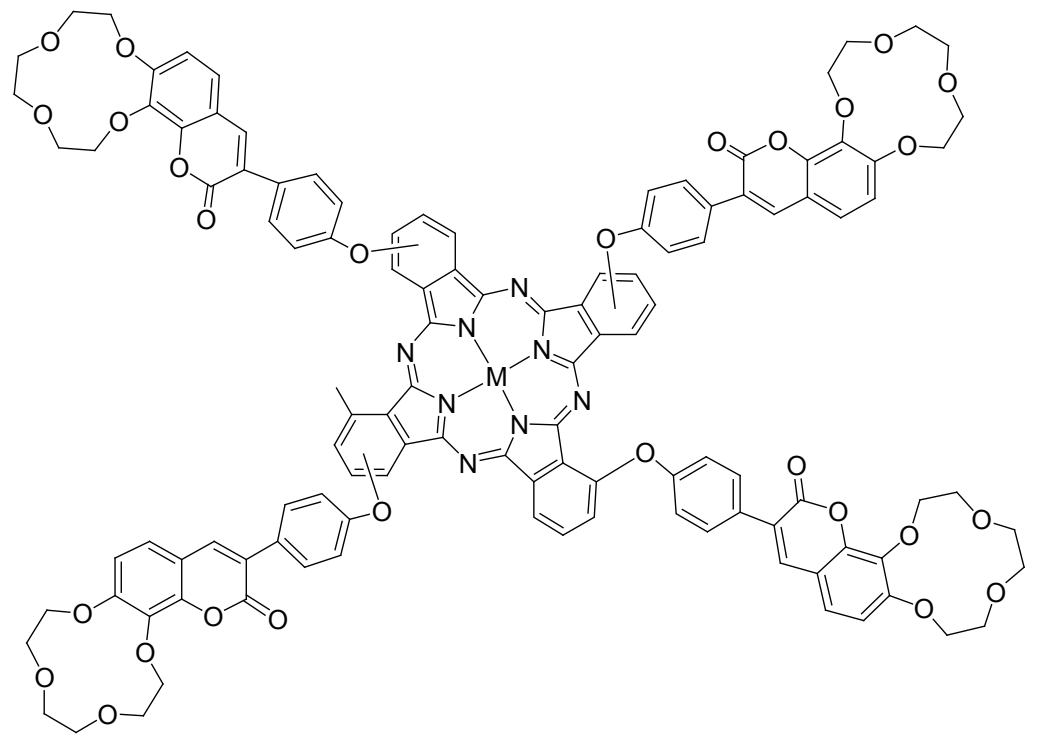

$M=C u(15 d), C o$ (15e), Zn (15f)

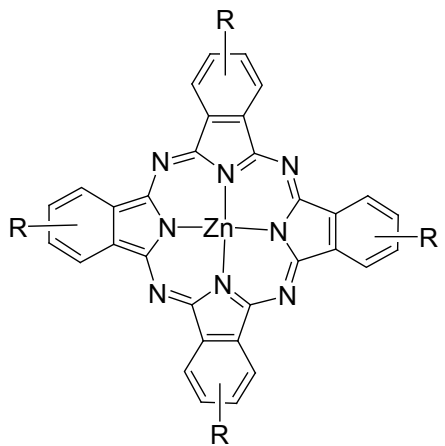

16a $R=$<smiles>CCCC[N+](C)(CCC)CCS</smiles>

16b $R=$<smiles>CCCC[N+](C)(CCCC)CCCO</smiles>

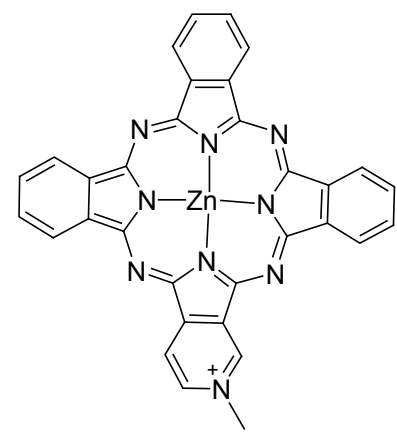

$17 a$

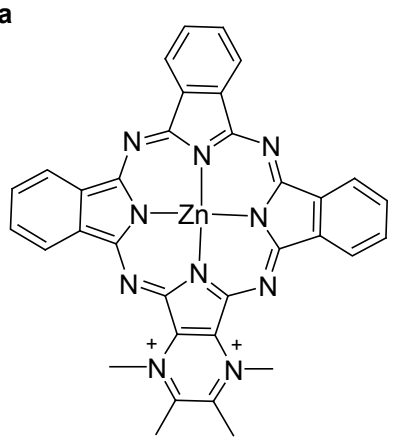

$17 \mathrm{c}$

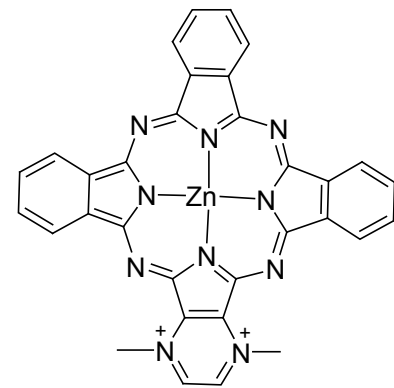

$17 b$

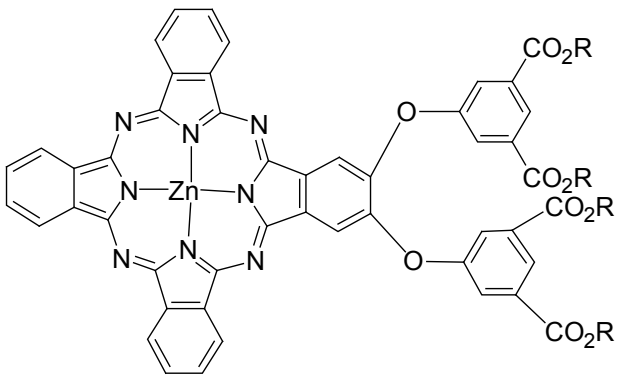

18b R $=\left(\mathrm{CH}_{2} \mathrm{CH}_{2} \mathrm{O}_{3} \mathrm{Me}\right.$

18c $\mathrm{R}=\left(\mathrm{CH}_{2} \mathrm{CH}_{2} \mathrm{O}_{12} \mathrm{Me}\right.$ 
$2.6 \mu \mathrm{mol} / \mathrm{L}$, 可能的原因是 $\mathbf{1 8 c}$ 有 4 个 PEG550 的侧链, 更多的 $\left(\mathrm{OCH}_{2} \mathrm{CH}_{2}\right)_{12}$ 单元导致更强的偶极-偶极相互作 用使 18c 更容易聚集. 被激发时, 18a 具有更强的荧光, 表明 18a 在细胞培养介质中聚集程度更低些. HT2 细胞 荧光图表明细胞质中充满了 18a 和 $18 \mathrm{~b}$, 而几乎未见 18c. 无需表面活性剂, 18a 可在水或细胞培养介质中形 成纳米粒子，根据制备方法的不同，纳米粒子半径为 $6.3 \sim 79.8 \mathrm{~nm}$, 对 $\mathrm{HT} 29$ 细胞的半抑制浓度 $\left(\mathrm{IC}_{50}\right)$ 为 $0.43 \sim 0.56 \mu \mathrm{mol} / \mathrm{L}$.

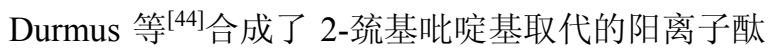
菁化合物 19a 和 19b, 在 DMSO 中 $19 \mathrm{a}$ 和 $19 \mathrm{~b}$ 未发生聚 集现象, 具有荧光; 19a 和 $19 b$ 虽然在水中具有良好的溶 解性, 但也发生一定程度的聚集, 聚集体的含量分别为 3.7 和 6.4, 这导致其不发射苂光. 由于牛血清蛋白中有 色氨酸残基, 在 $348 \mathrm{~nm}$ 左右发射苂光, 牛血清蛋白与 19a 和 19b 间的强相互作用导致牛血清蛋白的荧光被淬 灭, 结果表明, 在水中, 19a 比 19b 更有效地淬灭牛血清 蛋白的荧光, 其淬灭常数分别为 $1.16 \times 10^{5}$ 和 $0.55 \times 10^{5}$
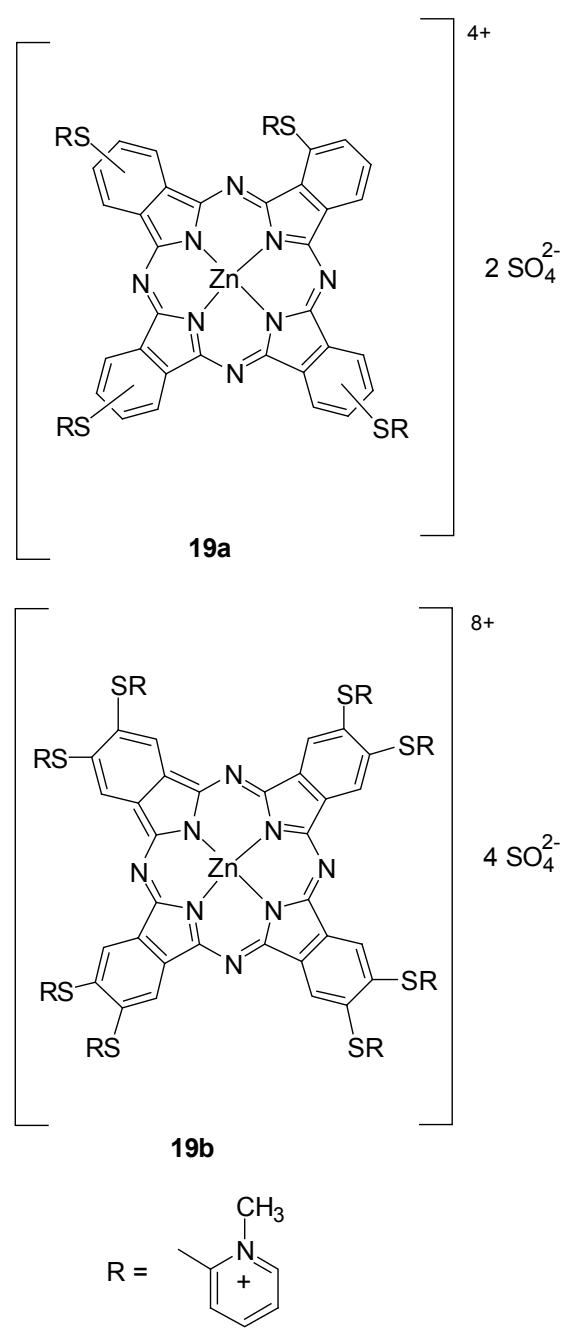

$\mathrm{mol}^{-1}$. 由于 $19 \mathrm{a}$ 和 $19 \mathrm{~b}$ 可与牛血清蛋白发生强相互作 用，表明它们作为光敏剂很容易被运送到血液中.

查尔酮是血管干扰试剂, 可快速地和定向地破坏肿 瘤细胞新生血管系统, Tuncel 等 ${ }^{[45}$ 将具有抗血管增生的 查尔酮与锌酞菁偶联, 得到抗血管增生和光动力治疗双 重功能的查尔酮-锌酞菁偶联化合物 $\mathbf{2 0}$, 在紫外光谱中, 由于查尔酮的吸收峰处于锌酞菁的 B 带，增加了 20 的 B 带吸收峰强度, 但其 $\mathrm{Q}$ 带的吸收峰强度未受影响. 在水/ 正辛醇体系中，由于 4 个亲水的 $\left(\mathrm{OCH}_{2} \mathrm{CH}_{2}\right)_{4}$ 连接基不足 以平衡唒菁环和查尔酮芳香环的疏水性，因此, 20 全处 于正辛醇相中.

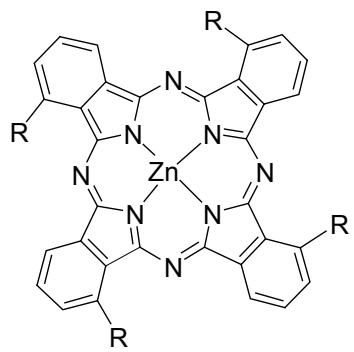<smiles>[R]OCCCCCC(=O)Nc1cc(/C=C/C(=O)c2cc(OC)c(OC)c(OC)c2)ccc1C</smiles>

Nombona 等 ${ }^{[46]}$ 合成了末端含 $\mathrm{SH}$ 的锌酞菁化合物 21, 在 DMF 和 DMSO 中, 21 荧光量子效率分别为 0.11 和 0.14, 而在 DMSO (2\%)/PBS/Triton X 100 中由于 21 聚集作用使其荧光量子效率低于 0.01 , 以成纤维细胞和 乳腺癌 MCF-7 细胞为研究对象, 考察了 21, 21 偶联纳米 金和 21 包裹于脂质体时的 PDT 效果. 细胞增殖试验表 明：对非恶性细胞的最优光毒性效果是 $4.5 \mathrm{~J} \cdot \mathrm{cm}^{-2}$,包裹 于脂质体中的 21 显示了对乳腺癌 MCF-7 细胞良好的 PDT 效果, 而与纳米金偶联的 21 只是具有中等程度 PDT 效果.

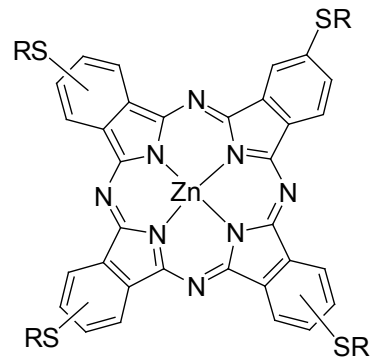

21<smiles>[R]=CCCCCCS</smiles> 


\section{3 二氢卟吩类光敏剂}

将卟啉分子中的一个双键直接还原可生成二氢卟 吩, 如目前常用的叶绿素 a 降解产物-二氢卟吩 e6 (chlorin e6) 是一种性能优良的光敏剂, 与目前报导和使 用的血卟啉醚类、光敏素 II (photofrin II)等卟啉类光敏 剂相比, 具有分子结构明确、红外区吸收系数大、光动 力反应能力强以及毒副作用小等诸多优点, 因此正在发 展成为新一代理想的光动力治癌药物.

\section{1 合成方法}

主要有还原法和氧化法合成二氢卟酚, Whitlock 等 ${ }^{[47]}$ 采用对甲苯磺酰肼还原四苯基卟啉得到得到二氢 卟酚和细菌二氢卟酚酞(bacteriochlorin) (Eq. 5), 利用它 们碱性的差异, 先采用抽提然后用柱层析法来进行分 离. 但是, 因为它们的极性非常接近, 必须采取高效液 相色谱或薄层色谱才能完全分离. Brôckner 等 ${ }^{[88]}$ 采用 $\mathrm{OsO}_{4}$ 氧化法得到邻二羟基二氢卟酚(Eq. 6), 邻二羟基的 存在一定程度上增加了垂直于卟啉平面的亲水性, 这或 许影响到它的生物分布, 与沿卟啉平面的亲水性药物相 比, 它和生物膜的相互作用会有所不同.
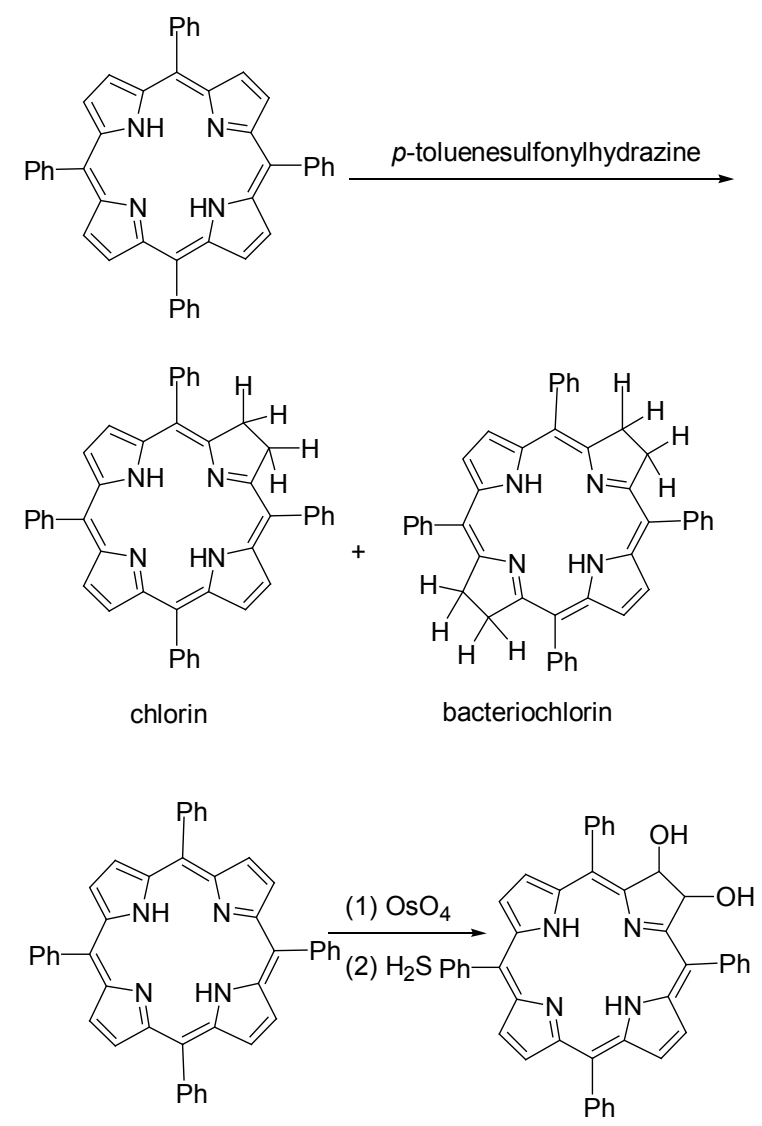

\section{2 二氢卟吩衍生物}

限制大多数光敏剂效率提高的因素是 $\pi$-芳香大环
间强烈的相互吸引作用引起光敏剂自聚集, 这种相互作 用主要受溶剂、样品浓度、温度以及光敏剂与生物分子 特异相互作用的影响. 由于自聚集可降低单重态氧和三 重态量子产率、荧光量子产率等, 不少研究者采取各种 方法在大环外围引入空间位阻大的取代基来减少溶质一 溶质或增加溶质-溶剂相互作用 ${ }^{[49,50]}$, 如叔丁基常被引 入到酞菁和萗酞菁化合物中 ${ }^{[51]}$ 或合成柱栏式卟啉 ${ }^{[52]}$ 等, 薄荷基比叔丁基具有更大的空间位阻效应 ${ }^{[49]}$ ，已有报 道将薄荷基引入分子结构中合成新型的光敏剂, 具有在 溶液中不易聚集的特性. 也有不少研究者将有利于聚集 和解聚集的取代基引入到同一分子中 ${ }^{[53]}$, 分别是引入 可形成氢键的基团和避免环的平面性的取代基. 另外, 将光敏剂负载到纳米粒子上也可有效地避免聚集.

Uchoa 等 ${ }^{[54]}$ 通过 Diels-Alder 加成反应合成一类非平 面和刚性 “L” 型的新型二氢卟吩光敏剂 $22 \mathbf{a} \sim 24 \mathbf{a}$ 和 $22 b \sim 24 b$, 该类光敏剂拥有较小的核和空间位阻较大 的轴向取代基, 即使在 $10^{-2} \mathrm{~mol} / \mathrm{L}$ 高浓度下, 分子间的 自聚集完全被阻止. 所有化合物均比二氢卟吩、卟啉的 苂光量子产率高, 在甲醇中测得荧光量子产率数据为 $0.12 \sim 0.17$, 在 $\mathrm{CH}_{3} \mathrm{CN} / \mathrm{H}_{2} \mathrm{O}$ 中的单重态氧量子产率也很 高, 为 $0.52 \sim 0.71$.

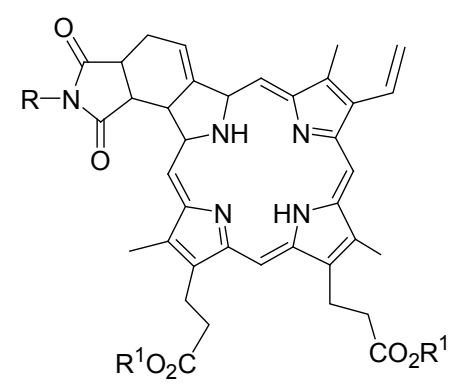

$$
\begin{aligned}
& \text { 22a } \mathrm{R}=\text { phenyl, } \mathrm{R}^{1}=\mathrm{Me} \\
& \text { 23a } \mathrm{R}=\text { octyl, } \mathrm{R}^{1}=\mathrm{Me} \\
& \text { 24a } \mathrm{R}=p \text {-nitrophenyl, } \mathrm{R}^{1}=\mathrm{Et}
\end{aligned}
$$

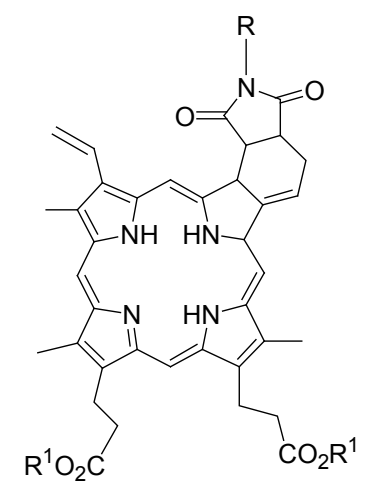

$$
\begin{aligned}
& \text { 22b } \mathrm{R}=\text { phenyl, } \mathrm{R}^{1}=\mathrm{Me} \\
& \text { 23b } \mathrm{R}=\text { octyl, } \mathrm{R}^{1}=\mathrm{Me} \\
& \text { 24b } \mathrm{R}=p \text {-nitrophenyl, } \mathrm{R}^{1}=\mathrm{Me}
\end{aligned}
$$


在二氢卟吩 e6 (chlorin e6)的 $17^{3}$-, $15^{2}$-和 $13^{1}$-位引入 赖氨酸和天冬氨酸残基得到 3 个区域异构的二氢卟吩 e6 衍生物 ${ }^{[55]}$, 体外 HEp2 癌细胞的研究结果表明: $15^{2}$ 赖氨酸残基功能化的二氢卟吩 e6 在细胞内聚集最多, 但 $13^{1}$-赖氨酸残基功能化的二氢卟吩 e6 的光毒性最高, 这些数据表明光敏剂的的生物效率取决于氨基酸与二 氢卟吩 $\mathrm{e} 6$ 偶联的位点, 很可能与其分子构象有关. 对这 3 个区域异构的二氢卟吩 e6 衍生物进行分子模拟发现: $17^{3}$ 位取代的二氢卟吩 $\mathrm{e} 6$ 是 $\mathrm{L}$ 型的, $13^{1}$ 位取代的二氢卟 吩 e6 是近乎线性型的, 且其 PDT 效果比目前商品化的 $15^{2}$ 位取代的二氢卟吩 e6 更有效.

$\beta$ 位未被取代的二氢卟吩被称为 Temoporfin, 在欧 洲已被批准用于临床治疗颈癌, 但存在易被氧化、制备 时不易与原料和副产物分离的缺点, 一般需用昂贵且有 毒的 $\mathrm{OsO}_{4}$ 作为氧化剂合成 $\beta$-二羟基取代的二氢卟吩, Wiehe 等 ${ }^{[56]}$ 采用 “无 $\mathrm{OsO}_{4}$ ” 的策略、并通过二酮 Temoporfin 的亲核加成反应合成 $\beta$ 位功能化的 Temoporfin 化合物 25a 25c, 25a 和 $25 \mathrm{c}$ 的单线态氧量 子产率与 Temoporfin 相当, 而 $\mathbf{2 5 b}$ 的单线态氧量子产率 是 Temoporfin 的 1.56 倍. 以体外人类腺癌 HT-29 细胞 为研究对象, 发现 $25 \mathrm{a} \sim 25 \mathrm{c}$ 均未表现出暗毒性, 25a 和 $25 \mathrm{c}$ 在 2 和 $10 \mu \mathrm{mol} / \mathrm{L}$ 时候均显示出光毒性, 与 Temoporfin 的光毒性相当, 而 $\mathbf{2 5 b}$ 的光毒性更低些, 只 是在 $10 \mu \mathrm{mol} / \mathrm{L}$ 时表现出光毒性.
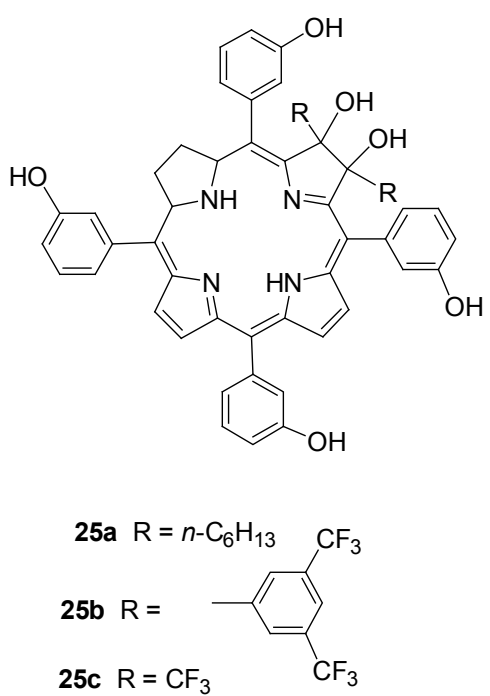

为了改善二氢卟吩的肿瘤选择性和水溶性, Zhang 等 ${ }^{\left[{ }^{57}\right]}$ 合成了新型的二氢卟吩衍生物 $\mathbf{2 6}$, 以体外乳腺癌 MDA-MB-231 细胞为研究对象, 发现将 26 负载到脂质 体后, 在 $4 \mathrm{~h}$ 内 26 能快速地进入 MDA-MB-231 细胞内, 大部分光敏剂定位于细胞质区域, 小部分光敏剂定位于 线粒体中. 此外还研究了 26 在移植瘤小鼠体内吸收、分 布及代谢的动态变化, 发现脂质体介导的 26 可诱导细
胞凋亡，对肿瘤细胞有好的选择性并可快速地共体内清 除. 上述研究结果表明 26 包裹到脂质体中可显著增加 其抗肿瘤细胞的 PDT 活性, 对肿瘤细胞产生严重损伤, 而对正常细胞却无影响.

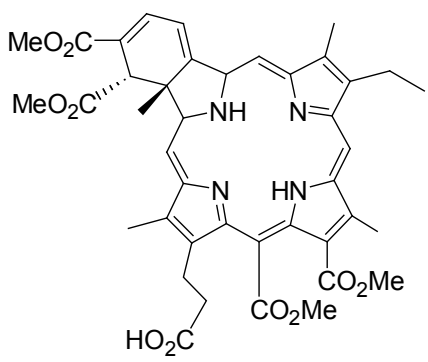

26

叶绿素类二氢卟吩的非对称性化学结构、多取代活 性官能团和稳定的芳香性共轭环系, 是保证光敏剂具有 良好的理化性质和 PDT 活性的基础条件. 王进军课题 组在二氢卟吩类衍生物的合成方面做了深入、系统的研 究工作. 以焦脱镁叶绿酸-a 甲酯为起始原料, 合成了超 过 $700 \mathrm{~nm}$ 长波吸收的 $\beta, \beta$-二氧亚甲基取代的叶绿素类 二氢卟吩衍生物 ${ }^{[58]}$ 、具有新型外接环碳架结构的叶绿素 类二氢卟吩衍生物 ${ }^{[59]} 、 \mathrm{C}-3$-吡唑啉基取代的叶绿素类二 氢卟吩衍生物 ${ }^{[60]}$ 、多种 $\mathrm{C}(3)$-多酮基取代的二氢卟吩衍

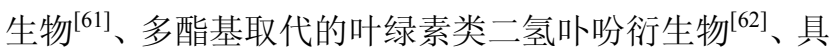
有叶绿素-a 基本碳架的氯代二氢卟吩衍生物 ${ }^{[6]}$ 和叶绿 素基本碳架的苯并咪唑并红紫素-18 衍生物 ${ }^{[64]}$. 此外, 以红紫素-18 甲酯为原料, 他们还开展了红紫素-18 的 胺解反应 ${ }^{[65]}$ 、卤化反应 ${ }^{[6]}$ 及其二氢卟吩类衍生物的合成 研究, 以及叶绿素- $\mathrm{a}^{[67]}$ 、叶绿素- $\mathrm{b}^{[68]}$ 和脱镁叶绿酸-a 甲 酯 ${ }^{[69]}$ 的降解及其二氢卟吩类衍生物的合成工作.

\section{4 展望}

综上所述，从最初的血卟啉到目前的各种功能卟啉 衍生物, 卟啉类光敏剂在光动力诊断和治疗中的应用 越来越广泛，虽然大量的卟啉衍生物已被设计合成并进 入临床应用，但根据卟啉分子的光敏化氧化的抗癌机 制, 来确定光敏药物的结构与抗癌效率之间关系方面还 不够完善, 还有很多问题亟待进一步深入研究, 如: (1) 光敏剂的化学结构和电子性质是影响其光生物活性和 光动力性质的重要因素, 需深入研究卟啉化学结构与 PDT 效能的关系; (2)合成各种基团修饰的卟啉类化合 物, 特别是控制修饰基团的化学性质及光学活性, 以改 善光敏剂的靶向性、渗透性、吸收性及代谢方面的特性 来达到高效低毒的目的; (3)新型卟啉类光敏剂的合成方 法及制备、分离纯化等过程有待工业化. 相信随着卟啉 类光敏剂研究工作的不断完善, 作为一种非侵害性治疗 
方法, 光动力疗法必将具有更加优良的作用效果和更加 广泛的应用范围.

\section{References}

[1] Ethirajan, M.; Chen, Y. H.; Joshi, P.; Pandey, R. K. Chem. Soc. Rev. 2011, 40, 340.

[2] Lovell, J. F.; Liu, T. W. B.; Chen, J.; Zheng, G. Chem. Rev. 2010, 110, 2839.

[3] Senge, M. O. Chem. Commun. 2011, 47, 1943.

[4] Adler, A. D.; Longo, F. R.; Finarelli, J. D.; Goldmacher, J.; Assour, J.; Korsahoff, L. J. Org. Chem. 1967, 32, 476.

[5] Lindsey, J. S.; Sehreiman, I. C.; Hsu, H. C.; Kearney, P. C.; Marguerettaz, A. M. J. Org. Chem. 1987, 52, 827.

[6] Ayabe, M.; Yamashita, K.; Sada, K.; Shinkai, S.; Ikeda, A.; Sakamoto, S.; Yamaguchi, K. J. Org. Chem. 2003, 68, 1059.

[7] Taniguchi, S.; Hasegawa, H.; Yanagiya, S.; Tabeta, Y.; Nakano, Y.; Takahashi, M. Tetrahedron 2001, 57, 2103.

[8] Montforts, F. P.; Gerlach, B.; Hoeper, F. Chem. Rev. 1994, 94, 327

[9] Liu, W. K.; Liu, C. Z.; Gong, C. J.; Lin, W. Y.; Guo, C. C. Bioorg. Med. Chem. Lett. 2009, 19, 1647.

[10] Zieba, G.; Rojkiewicz, M.; Kozik, V.; Jarzembek, K.; Jarczyk, A.; Sochanik, A.; Kus, P. Monatsh. Chem. 2012, 143, 153.

[11] Zhang, P.; Zhang, S.-F. Chin. J. Org. Chem. 2010, 30, 775 (in Chinese). (张沛, 张淑芬, 有机化学, 2010, 30, 775.)

[12] Ballut, S.; Naud-Martin, D.; Loock, B.; Maillard, P. J. Org. Chem. 2011, 76, 2010.

[13] Vedachalam, S.; Choi, B. H.; Pasunooti, K. K.; Ching, K. M.; Lee, K.; Yoon, H. S.; Liu, X.-W. Med. Chem. Commun. 2011, $2,371$.

[14] Huang, Q.-M.; Wang, S.-W.; Li, Q.; Pan, W.; Deng, P.-X.; Zhou, H.; Pan, Z.-Q. Chem. J. Chin. Univ. 2012, 33, 732 (in Chinese). (黄齐茂, 王司卫, 李清, 潘威, 邓鹏星, 周红, 潘志权, 高等学 校化学学报, 2012, 33, 732.)

[15] Giuntini, F.; Alonso, C. M. A.; Boyle. R. W. Photochem. Photobiol. Sci. 2011, 10, 759 .

[16] Serra, V. V.; Zamarrón, A.; Faustino, M. A. F.; Cruz, M. C. I.; Blázquez, A.; Rodrigues, J. M. M.; Neves, M. G. P. M. S.; Cavaleiro, J. A. S.; Juarranz, A.; Sanz-Rodríguez, F. Bioorg. Med. Chem. 2010, 18, 6170.

[17] Amessou, M.; Carrez, D.; Patin, D.; Sarr, M.; Grierson, D. S.; Croisy, A.; Tedesco, A. C.; Maillard, P.; Johannes, L. Bioconjugate Chem. 2008, 19, 532.

[18] Sol, V.; Chaleix, V.; Granet, R.; Krausz, P. Tetrahedron 2008, 64, 364.

[19] Makky, A.; Michel, J. P.; Briand, A.; K. E.; Maillard, P.; Rosilio, V. Langmuir 2010, 26, 12761.

[20] Zeng, Z.; Liao, Z.-Y.; Tang, T.-S.; Chen, C.-S. Chin. J. Org. Chem. 2007, 27, 24 (in Chinese). (曾卓, 廖子英, 唐天声, 陈超森, 有机化学, 2007, 27, 24.)

[21] Leroy, J.; Bondon, A. Eur. J. Org. Chem. 2008, 417.

[22] Costa, J. I. T.; Tome, A. C.; Neves, M. G. P. M. S.; Cavaleiro, J. A. S. J. Porphyrines Phthalocyanines 2011, 15, 1116.

[23] Hirohara, S.; Obata, M.; Alitomo, H.; Sharyo, K.; Ando, T.; Yano, S.; Tanihara, M. Bioconjugate Chem. 2009, 20, 944.

[24] McCarthy, J. R.; Bhaumik, J.; Merbouh, N.; Weissledera, R. Org. Biomol. Chem. 2009, 7, 3430.

[25] Li, J. Z.; Wang, J. J.; Yoon, I.; Cui, B. C.; Shim. Y. K. Bioorg. Med. Chem. Lett. 2012, 22, 1846.

[26] Achelle, S.; Couleaud, P.; Baldeck, P.; Teulade-Fichou, M.-P.; Maillard, P. Eur.J. Org. Chem. 2011, 1271.
[27] Zhan, P.-Y.; Li, D.-F.; Wang, J.-J. Chin. J. Org. Chem. 2008, 28, 2039 (in Chinese). (战佩英, 李东风, 王进军, 有机化学, 2008, 28, 2039.)

[28] Jiang, H.-W.; Xiao, J.-C. Chin. J. Org. Chem. 2009, 29, 1750 (in Chinese). (蒋华卫, 肖吉昌, 有机化学, 2009, 29, 1750.)

[29] Xue, Z.-L.; Shen, Z.; Mack, J.; Kuzuhara, D.; Yamada, H.; Okujima, T.; Ono, N.; You, X.-Z.; Kobayashi, N. J. Am. Chem. Soc. 2008, 130, 16478.

[30] Xue, Z.-L.; Mack, J.; Lu, H.; Zhang, L.; You, X.-Z.; Kuzuhara, D.; Stillman, M.; Yamada, H.; Yamauchi, S.; Kobayashi, N.; Shen, Z. Chem. Eur. J. 2011, 17, 4396.

[31] Xu, H.-J.; Mack J.; Descalzo, A. B.; Shen, Z.; Kobayashi, N.; You, X.-Z.; Knut Rurack, Chem. Eur. J. 2011, 17, 8965.

[32] Torres, T. J. Porphyrines Phthalocyanines 2000, 4, 325. .

[33] Yuan, J.-Z.; Cheng, G.-Z.; Ji, Z.-P. J. Wuhan Univ. (Nat. Sci. Ed.) 1999, 45, 8171 (in Chinese).

(袁吉志, 程功臻, 季振平, 武汉大学学报 (自然科学版), 1999, 45, 8171.)

[34] Leznoff, C. C.; Snirskaya, P.; Khouw, B.; Cerny, R. L.; Cerny, R. L.; Seymour, P.; Lever, A. B. P. J. Org. Chem. 1991, 56, 82.

[35] Kobayashi, N.; Kondo, R.; Nakajima, S.; Osa, T. J. Am. Chem. Soc. 1990, $112,9640$.

[36] Uslan, C.; Sesalan, B. S. Dyes Pigm. 2012, 94, 127.

[37] Ke, M.-R.; Yeung, S.-L.; Fong, W.-P.; Ng, D. K. P.; Lo, P.-C. Chem. Eur. J. 2012, 18, 4225.

[38] Nyman, E.; Hynninen, P. H. J. Photochem. Photobiol. Biol. 2004, $73,1$.

[39] Çamur, M.; Durmus, M.; Özkaya, A. R.; Bulut, M. Inorg. Chim. Acta 2012, 383, 287.

[40] Longo, J. P. F.; Leal, S. C.; Simioni, A. R.; Almeida-Santos, M. F. M.; Tedesco, A. C.; Azevedo, R. B. Lasers Med. Sci. 2012, 27, 575.

[41] Gauna, G. A.; Marinob, J.; Viora, M. C. G.; Roguinb, L. P.; Awrucha, J. Eur. J. Med. Chem. 2011, 46, 553.

[42] Tempesti, T. C.; Alvarez, M. G.; Durantini, E. N. Dyes Pigm. 2011, 91,6 .

[43] Bai, M.; Lo, P.-C.; Ye, J.; Wu, C.; Fong W.-P.; Ng, D. K. P. Org. Biomol. Chem. 2011, 9, 7028.

[44] Durmus, M.; Yaman, H.; Göl, C.; Ahsen, V.; Nyokong, T. Dyes Pigm. 2011, 91, 153.

[45] Tuncel, S.; Fournier-dit-Chabert, J.; Albrieux, F.; Ahsen, V.; Ducki, S.; Dumoulin, F. Org. Biomol. Chem. 2012, 10, 1154.

[46] Nombona, N.; Maduray, K.; Antunes, E.; Karsten, A.; Nyokong, T. J. Photochem. Photobiol. Biol. 2012, 107, 35.

[47] Whitlock, J. H. W.; Hunamor, R.; Oester, M. Y.; Bower, B. K. J. Am. Chem. Soc. 1969, 91, 7485.

[48] Brôckner, C.; Dolphin, D. Tetrahedron Lett. 1995, 36, 9425.

[49] de Oliveira, K. T.; de Assis, F. F.; Ribeiro, A. O.; Neri, C. R.; Fernandes, A. U.; Baptista, M. S.; Lopes, N. P.; Serra, O. A.; Iamamoto, Y. J. Org. Chem. 2009, 74, 7962.

[50] Rossi, L. M.; Silva, P. R.; Vono, L. L.; Fernandes, A. U.; Tada, D. B.; Baptista, M. S. Langmuir 2008, 24, 12534.

[51] Sibrian-Vazquez, M.; Ortiz, J.; Nesterova, I. V.; Fernandez- Lazaro, F.; Sastre-Santos, A.; Soper, S. A.; Vicente, M. G. Bioconjugate Chem. 2007, 18, 410

[52] Lawrence, D. S.; Gibson, S. L.; Nguyen, M. L.; Whittemore, K. R.; Whitten, D. G.; Hilf, R. Photochem. Photobiol. 1995, 61, 90.

[53] Barkigia, K. M.; Renner, M. W.; Senge, M. O.; Fajer, J. J. Phys. Chem. B 2004, 108, 2173.

[54] Uchoa, A. F.; de Oliveira, K. T.; Baptista, M. S.; Bortoluzzi, A. J.; Iamamoto, Y.; Serraz, O. A. J. Org. Chem. 2011, 76, 8824.

[55] Jinadasa, R. G. W.; Hu, X.-K.; Vicente, M. G. H.; Smith, K. M. J. 
Med. Chem. 2011, 54, 7464.

[56] Aicher, D.; Gräfe, S.; Stark, C. B. W.; Wiehe, A. Bioorg. Med. Chem. Lett. 2011, 215808.

[57] Zhang, J.-L.; Deng, L.; Yao, J.-Z.; Gu, P.; Yang, F.; Wang, X.-X.; Liu, W.; Zhang, Y.-Y.; Ke, X.-F.; Jing, X.-L.; Chen, J.-M. Bioorg. Med. Chem. 2011, 19, 5520.

[58] Wu, J.; Yin, J.-G.; Liu, R.-R.; Yang, Z.; Wang, Z.; Wang, J.-J. Chin. J. Org. Chem. 2012, 32, 149 (in Chinese).

(武进, 殷军港, 刘再舟, 杨泽, 王振, 王进军, 有机化学, 2012, 32,149 .)

[59] Wu, X.-R.; Liu, C.; Yang, Z.; Yao, N.-N.; Wang, J.-J. Chin. J. Org. Chem. 2012, 32, 632 (in Chinese).

(邬旭然, 刘超, 杨泽, 姚楠楠, 纪建业, 王鲁敏, 荆济荣, 韩光 范, 王进军, 有机化学, 2012, 32, 632.)

[60] Yin, J.-G.; Li, Y.-W.; Li, J.-Z.; Zhang, Q.; Pei, W.; Wang, J.-J. Chin. J. Org. Chem. 2011, 31, 1213 (in Chinese).

(殷军港, 李韵伟, 李家柱, 张千, 裴文, 王进军, 有机化学, 2011, 31, 1213.)

[61] Wang, J.-J.; Li, F.-G.; Li, Y.-W. Chin. J. Org. Chem. 2011, 31, 68 (in Chinese). (王进军, 李付国, 李韵伟, 有机化学, 2011, 31, 68.)

[62] Yin, J.-G.; Wang, Z.; Yang, Z.; Liu, C.; Zhao, L.-L.; Wang, J.-J. Chin. J. Org. Chem. 2012, 32, 360 (in Chinese). (殷军港, 王振, 杨泽, 刘超, 赵丽丽, 王进军, 有机化学, 2012, 32, 360.)

[63] Wang, J.-J.; Zhao, L.-L.; Li, J.-Z. Chin. J. Org. Chem. 2009, 29,
1598 (in Chinese).

(王进军, 赵丽丽, 李家柱, 有机化学, 2009, 29, 1598.)

[64] Liu, R.-R.; Wang, L.-M.; Yin, J.-G.; Wu, J.; Liu, C.; Zhang, P.; Wang, J.-J. Chin. J. Org. Chem. 2012, 32, 318 (in Chinese). (刘申手, 王鲁敏, 殷军港, 武进, 刘超, 张朋, 王进军, 有机化 学, 2012, 32, 318.)

[65] Wang, P.; Yang, Z.; Li, J.-Z.; Yao, N.-N.; Wang, J.-J. Chin. J. Org. Chem. 2012, 32, 368 (in Chinese).

(王朋, 杨泽, 李家柱, 姚楠楠, 王进军, 有机化学, 2012, 32, 368.)

[66] Liu, R.-R.; Yin, J.-G.; Li, J.-Z.; Wu, J.; Chen, G.-L,; Jin, Y.-X.; Wang, J.-J. Chin. J. Org. Chem. 2012, 32, 544 (in Chinese). (刘申再, 殷军港, 李家柱, 武进, 陈冠龙, 金英学, 王进军, 有 机化学, 2012, 32, 544.)

[67] Wang, J.-J.; Zhang, P.; Wang, P.; Chen, G.-L.; Li, F.-G. Chin. J. Org. Chem. 2010, 30, 1192 (in Chinese).

(王进军, 张朋, 王朋, 陈冠龙, 李付国, 有机化学, 2010, 30, 1192.)

[68] Wu, J.; Yin, J. G.; Zhang, Q.; Sun, C.-M.; Li, F.-G.; Pei, W.; Wang, J.-J. Chin. J. Org. Chem. 2011, 31, 1653 (in Chinese). (武进，殷军港，张千，孙传民，李付国，裴文，王进军，有机化 学, 2011, 31, 1653.)

[69] Yin, J.-G.; Wu, X.-R.; Liu, C.-L.; Zhao, L.-L; Jin, Y.-X.; Wang, J.-J. Chin. J. Org. Chem. 2011, 31, 1870 (in Chinese).

(殷军港, 邬旭然, 刘春林, 赵丽丽, 金英学, 王进军, 有机化学, 2011, 31, 1870.) 